NBER WORKING PAPER SERIES

\title{
GLOBALIZATION, LABOR INCOME, AND POVERTY IN MEXICO
}

\author{
Gordon H. Hanson
}

Working Paper 11027

http://www.nber.org/papers/w11027

\author{
NATIONAL BUREAU OF ECONOMIC RESEARCH \\ 1050 Massachusetts Avenue \\ Cambridge, MA 02138 \\ January 2005
}

I thank Julie Cullen, Esther Duflo, Ann Harrison, Jim Levinsohn, and participants in the NBER Conference on Globalization and Poverty for helpful comments. Jeffrey Lin provided excellent research assistance.The views expressed herein are those of the author(s) and do not necessarily reflect the views of the National Bureau of Economic Research.

(C) 2005 by Gordon H. Hanson. All rights reserved. Short sections of text, not to exceed two paragraphs, may be quoted without explicit permission provided that full credit, including (C) notice, is given to the source. 
Globalization, Labor Income, and Poverty in Mexico

Gordon H. Hanson

NBER Working Paper No. 11027

January 2005

JEL No. F1

\begin{abstract}
In this paper, I examine changes in the distribution of labor income across regions of Mexico during the country's decade of globalization in the 1990's. I focus the analysis on men born in states with either high-exposure or low-exposure to globalization, as measured by the share of foreign direct investment, imports, or export assembly in state GDP. Controlling for regional differences in the distribution of observable characteristics and for initial differences in regional incomes, the distribution of labor income in high-exposure states shifted to the right relative to the distribution of income in low-exposure states. This change was primarily the result of a shift in mass in the income distribution for low-exposure states from upper-middle income earners to lower income earners. Labor income in low-exposure states fell relative to high-exposure states by $10 \%$ and the incidence of wage poverty (the fraction of wage earners whose labor income would not sustain a family of four at above-poverty consumption levels) in low-exposure states increased relative to high-exposure states by $7 \%$.
\end{abstract}

Gordon H. Hanson

IR/PS 0519

University of California, San Diego

9500 Gilman Drive

La Jolla, CA 92093-0519

and NBER

gohanson@ucsd.edu 


\section{Introduction}

There is now an immense body of literature on how globalization affects labor markets. Early research centered on the United States (Freeman, 1995; Richardson, 1995), motivated in part by an interest in understanding what caused marked changes in the U.S. wage structure during the 1980's and 1990's (Katz and Autor, 1999). A common theme in this work is that globalization - especially in the form of global outsourcing - has modestly but significantly contributed to increases in wage differentials between more and less-skilled workers (Feenstra and Hanson, 1999 and 2003). A small effect for international trade is perhaps not surprising, given the large size of the U.S. economy and the still limited role that trade plays in U.S. production and consumption (Feenstra, 1998; Freeman, 2003). Later research shifted attention to other countries, and to the developing world in particular, which in the 1980's began to lower barriers to trade and capital flows aggressively. The tendency for rising wage inequality to follow globalization is not limited to the United States or other rich countries. Expanding trade and capital flows have been associated with increases in the relative demand for skilled labor in many economies, including Chile (Pavcnik, 2003), Columbia (Attanasio, Goldberg, and Pavcnik, 2004), Hong Kong (Hsieh, 2003), Mexico (Feenstra and Hanson, 1997), and Morocco (Currie and Harrison, 1997), just to list a few recent examples. ${ }^{1}$

In most research to date, the focus has been on the relationship between globalization and earnings inequality. Fewer studies have examined how globalization affects income levels. This comes as something of a surprise, given the long-standing interest of developing-country research in how changes in policy affect the well-being of

\footnotetext{
${ }^{1}$ See Winters, McCulloch, and McKay (2004) and Pavcnik and Goldberg (2004) for surveys of the literature on globalization and income in developing countries.
} 
the poor. The relative lack of attention on the impact of globalization on poverty is perhaps partly attributable to methodology. The most established empirical techniques for identifying the effects of economic shocks, such as globalization or technological change, on earnings relate to estimating changes in the relative demand for labor of different skill types (Katz and Autor, 1999). The lack of attention may also reflect a U.S.-bias in the type of questions being asked. The strong emphasis in U.S. research on why earnings inequality has increased may have spilled over into research on other countries, partially crowding out other issues.

In this paper, I examine how the distribution of income changed in Mexico during country's decade of globalization in the 1990's. Taking the income distribution as the unit of analysis makes it possible to examine changes both in the nature of inequality reflected in the shape of the distribution - and in the level of income - reflected in the position of the distribution. Mexico is an interesting case because over the last two decades the country has aggressively opened its economy to the rest of the world. This process began with a unilateral liberalization of trade in 1985 , continued with the elimination of many restrictions on foreign capital in 1989, and culminated with the North American Free Trade Agreement (NAFTA) in 1994 (Hanson, 2004). ${ }^{2}$

The one study of which I'm aware that attempts to estimate the impact of trade liberalization on poverty in Mexico is Nicita (2004). He applies data from the Mexico's National Survey of Household Income and Expenditure to techniques developed by Deaton and Muellbauer (1980) to construct an estimate of how tariff reductions have

\footnotetext{
${ }^{2}$ See Chiquiar (2003) for a discussion of recent policy changes in Mexico. For other work on the labormarket implications of globalization in Mexico, see Ariola and Juhn (2003), Cragg and Epelbaum (1996), Farris (2003), Feliciano (2001), Revenga (1997), Hanson and Harrison (1999), and Robertson (2003). See Hanson (2004) for a review of this literature. For work on trade reform and wage inequality in Latin America, see Behrman, Birdsall, and Szekely (2003).
} 
affected household welfare. This exercise involves estimating the impact of tariff changes on domestic goods' prices, the impact of changes in goods' prices on the wages of different skill groups, and income and price elasticities of demand for different goods, and then combining these estimates to form an estimate of the change in real income due to tariffs. During the 1990's, tariff changes appeared to raise disposable income for all households, with richer households enjoying a $6 \%$ increase and poorer households enjoying a $2 \%$ increase. These income gains imply a $3 \%$ reduction in the number of households in poverty. Income gains are larger in regions closer to the United States, where tariff-induced price changes are larger. I will also find that proximity to world markets matters for income changes. By focusing on prices for final goods, the Deaton and Muellbauer (1980) approach taken by Nicita (2004) ignores other impacts of globalization, such as increases in foreign investment or increased trade in intermediate inputs. The approach I develop, which cannot relate specific policy changes to changes in income, does consider these other aspects of Mexico's economic opening.

An obvious empirical challenge in studying income distributions, rather than individuals or industries, is the paucity of degrees of freedom. Income distributions are aggregate entities, implying the number of observations is limited to the number of time periods in the sample. In my case, I really have only two observations, 1990 and 2000, corresponding to the most recent years in which Mexico conducted its census of population and housing. My strategy for identifying the impact of globalization on Mexico's income distribution is to exploit regional variation in exposure to foreign trade and investment. As discussed in section 2, geography and history have made states in Mexico's north and center highly exposed to globalization and left states in Mexico's 
south relatively disengaged from the global economy. I take states with high exposure to globalization to be the treatment group and states with low exposure to globalization to be the control group (leaving states with intermediate exposure to globalization out of the analysis). I then apply a difference-in-difference strategy by comparing the change in the income distribution for high-exposure states to the change in income distribution for lowexposure states during Mexico's globalization decade. Implicit in the analysis is the assumption is that labor is sufficiently immobile across regions of Mexico for regionspecific labor-demand shocks to affect regional differentials in labor income.

The analysis is complicated by a host of issues, three of which stand out. One is that income distributions change both because the characteristics of the underlying population of individuals change and because the returns to these characteristics change. To identify the effects of globalization, I want to examine changes in returns to characteristics (in my case, inter-regional differences in these changes), while holding the distribution of characteristics constant. To perform this exercise, I apply non-parametric techniques from DiNardo, Fortin, and Lemieux (1996) and Leibbrandt, Levinsohn, and McCrary (2004), which I describe in section 3. I also compare results from this approach to results from a more-standard parametric approach, both of which are presented in section 4. A second issue is that other shocks in the 1990's may also have had differential effects on regions with high versus low exposure to globalization. Candidate shocks include the privation and deregulation of industry, the reform of Mexico's landtenure system, and, most importantly, Mexico's peso crisis in 1994. The potential for these shocks to contaminate the analysis is an important concern, which I address by way of discussing qualifications to my results in section 5 . 
A third issue has to do with measurement. There are many components to income, including labor earnings, capital returns, rental income, government transfers, gifts, and remittances from family members abroad. Surveys that measure each of these components carefully, such as Mexico's National Survey of Household Income and Expenditure, are not representative across the regions of the country (Cortes et al., 2003), which makes it impossible to apply my estimation strategy to these data. Surveys that are representative across Mexico's regions, such as the Census of Population and Housing, measure labor income with relatively high precision, but lack complete data on other income categories. To ensure my data are regionally representative, I use the Mexican Census, and to minimize the impact of measurement error, I focus the analysis on labor income. Excluding other sources of income has the obvious drawback of limiting the analysis to labor earnings, rather than to the full distribution of income. ${ }^{3}$

To preview the results, states with high-exposure to globalization began the 1990's with higher incomes than low exposure states, even after controlling for regional differences in the observable characteristics of individuals. During the 1990's, lowexposure states had slower growth in labor income than high-exposure states. This took the form of a left-ward shift in the income distribution of low-exposure states relative to high-exposure states. The results of this income shift were (a) a decrease in average labor earnings of $10 \%$ for individuals from states with low exposure to globalization relative to individuals from states with high exposure to globalization, and (b) an increase in the incidence of wage poverty (the fraction of wage earners whose labor income would

\footnotetext{
${ }^{3}$ One interesting extension to my analysis would be to use Mexico's National Survey of Household Income and Expenditure to estimate the empirical relationship between labor income and poverty. One could then use this mapping to evaluate how the changes in labor income that I estimate (using data from the Census of Population and Housing) may have affected poverty.
} 
not sustain a family of four at above-poverty consumption levels) in low-exposure states of $7 \%$ relative to that in high-exposure states.

\section{Regional Exposure to Globalization}

\subsection{Data Sources}

Data for the analysis come from two sources. In 1990, I use the $1 \%$ microsample of the XII Censo General de Poblacion y Vivienda, 1990, and in 2000 I use a 10\% random sample of the $10 \%$ microsample of the XIII Censo General de Poblacion $y$ Vivienda, 2000. The sample is working age men with positive labor earnings. I focus on men, since labor-force participation rates for women are low and vary considerably over time, ranging from $21 \%$ in 1990 to $32 \%$ in 2000 . This creates issues of sample selection associated with who supplies labor outside the home. Compounding the problem, many women who report zero labor earnings may work in the family business or on the family farm. For men, problems of sample selection and measurement error also exist but appear to be less severe. Their labor-force participation rates vary less over time, rising modestly from $73 \%$ in 1990 to $74 \%$ in 2000 . Still, differences in labor-force participation over time and across regions could affect the results reported in section 4 . In section 3 , I discuss strategies to correct for self-selection into the labor force.

\subsection{The Opening of Mexico's Economy}

In Mexico, the last two decades have not been a quiet period. Since 1980, the country has had three currency crises, bouts of high inflation, and several severe macroeconomic contractions, the most recent of which occurred in 1995 following a large devaluation of the peso that precipitated the country's conversion from a fixed to a 
floating exchange rate. The liberalization of the country's trade and investment policies has been, in part, a response to this turmoil. Mexico's currency crises and ensuing contractions have had very negative consequences on the country's poor. Table 1 shows that poverty rates rose sharply after the 1995 peso crisis.

Mexico's economic opening began in 1982, when the government responded to a severe balance of payments crisis by easing restrictions on export assembly plants known as maquiladoras. In 1985, Mexico joined the General Agreement on Trade and Tariffs (GATT), which entailed cutting tariffs and eliminating many non-tariff barriers. In 1989, Mexico eased restrictions on the rights of foreigners to own assets in the country. In 1994, NAFTA consolidated and extended these reforms. Partly as a result of these policy changes, the share of international trade in Mexico's GDP has nearly tripled, rising from $11 \%$ in 1980 to $32 \%$ in 2002 . Mexico is now as closely tied to the U.S. economy as it has been at any point in its history. In 2002, the country sent $89 \%$ of its exports to and bought $73 \%$ of its imports from the United States. ${ }^{4}$

Mexico's maquiladoras, shown in Figure 1, have been instrumental in the country's export conversion. Between 1983 and 2002, real value added in maquiladoras grew at an average annual rate of $11 \%$, making it the most dynamic sector in the country. In 2002, these export assembly plants accounted for $45 \%$ of Mexico's manufacturing exports and $28 \%$ of the country's manufacturing employment (up from $4 \%$ in 1980). Their concentration in northern Mexico in part accounts for the differential regional impact of globalization in the country. A brief history of Mexico's trade policy reveals the origins of northern Mexico's advantage in export production.

\footnotetext{
${ }^{4}$ Concomitant with its economic opening, Mexico privatized state-owned enterprises, deregulated entry restrictions in many industries, and used wage and price restraints to combat inflation.
} 
In the 1940's, Mexico adopted a strategy of import substitution industrialization. To import most manufacturing products, firms had to obtain a license from the government and to pay moderate to high tariffs. In 1965, Mexico softened its import substitution strategy by allowing the creation of maquiladoras (Hansen, 1981). ${ }^{5}$ Firms could import free of duty the inputs, machinery, and parts needed for export assembly operations, as long as they exported all output. To ensure firms abided by this rule, they were required to buy a bond equal to the value of their imports that would be returned to them once they had exported all their imported inputs in the form of final goods (hence the term in-bond assembly plants). In contrast to other firms in the country, maquiladoras could be $100 \%$ foreign owned. Bureaucratic restrictions on maquiladoras kept the sector small until 1982, when the government streamlined regulation of the plants.

Initially, maquiladoras were required to locate within 20 miles of an international border or coastline. In 1972, the government relaxed these rules and allowed maquiladoras to locate throughout the country. However, the plants continued to concentrate near the United States. As seen in Figure 2, 83\% of maquiladora employment is still located in states on the U.S. border. Proximity to the U.S. market is motivated in part by a desire to be near U.S. consumers, to whom maquiladoras export most of their production, and in part by a desire to be near U.S. firms, who often manage Mexican maquiladoras out of offices based in U.S. border cities.

U.S. trade policies initially gave maquiladoras an advantage over other Mexican producers in exporting to the U.S. market. Prior to NAFTA, a U.S. firm that made

\footnotetext{
${ }^{5}$ The original motivation for this program was to create employment opportunities for Mexican workers returning to the country after working in the United States as temporary farm laborers under the Bracero Program. The U.S. government ended the Bracero Program in 1964 and the Mexican government was concerned that the returning workers would raise unemployment in border states.
} 
components, shipped them to a plant in Mexico for assembly, and then reimported the finished good only paid U.S. import duties on the value of Mexican labor and raw materials used in assembly. NAFTA ended this special status for maquiladoras by giving all Mexican firms duty free access to the U.S. market. ${ }^{6}$ Yet, as seen in Figure 1, NAFTA did little to stunt the growth of maquiladoras. In a purely legalistic sense, NAFTA did mean the end of the maquiladora regime; it eliminated the "in-bond" arrangement under which maquiladoras operated. However, Mexico's low wages continue to give the country a comparative advantage in the assembly of manufactured goods for the U.S. economy.

\subsection{Regional Exposure to Globalization}

Mexico's trade and investment reforms have dramatically increased the openness of its economy. These policies appear to have affected some parts of the country much more than others. Figure 3 plots the share of state GDP accounted for by valued added in maquiladoras during the 1990's against distance to the United States. For three of the six states that border the United States (Baja California, Chihuahua, Tamaulipas), the maquiladora share of GDP is over 18\%. For two of the three others (Coahuila, Sonora) it is over $8 \%$. In the rest of the country, the maquiladora share of GDP is below $5 \%$.

While maquiladoras are a large part of Mexico's exports, they are by no means the whole story. Export production also occurs in states with relatively large supplies of skilled labor, which have attracted multinational auto companies (as in Aguascalientes) and electronics producers (as in Jalisco). Figure 4 plots the share of foreign direct investment in state GDP against the share of maquiladora value added in state GDP, both

\footnotetext{
${ }^{6}$ With NAFTA, all firms in Mexico obtained duty-free access to the U.S. market as long as they comply with NAFTA rules of origin. NAFTA also exposes maquiladoras to rules of origin (from which they had been exempt previously), but now also allows the plants to sell goods on the Mexican market.
} 
averaged over the 1990's. While border states show up as high in both categories, other states have attracted foreign direct investment in forms besides maquiladoras. These include states in which Mexico's most important industrial cities are located (Mexico City, Federal District; Monterrey, Nuevo Leon; Guadalajara, Jalisco).

Beyond FDI and maquiladoras, some states are exposed to globalization by virtue of having ports and being large importers. This is seen in Figure 5, which plots FDI as a share of state GDP against imports as a share of state GDP. ${ }^{7}$ A few states, such as Yucatan and Sinaloa, have high imports, while attracting little in the way of FDI.

To categorize states as having high or low exposure to globalization, I use the three measures described in Figures 3-5: the share of maquiladora value added in state GDP, the share of FDI in state GDP, and the share of imports in state GDP (each averaged over the period 1993-1999). Using all three measures is important, since with the exception of FDI and imports they are relatively weakly correlated across states, as reported in Table 2. Table 3 reports the globalization measures for Mexico's 32 states, where states are sorted according to their average rank across the three measures. I select as states with high exposure to globalization those whose average rank across the three measures is in the top third (and that have at least one individual rank in the top third) and I select as states with low exposure to globalization those whose average rank is in the bottom third (and that have no single rank in the top third).

Of the 7 states with high-exposure to globalization, 5 share a border with the United States; of the 10 states with low-exposure to globalization, 5 are in southern Mexico. Historically, Mexico's north - with its more abundant mineral deposits, lower population densities, and closer proximity to the United States - has been relatively rich,

\footnotetext{
7 In Mexico, there are no data on exports at the state level (other than data on maquiladora exports).
} 
while Mexico's south - with its higher population densities and larger indigenous community - has been relatively poor. It is well known that since Mexico's economic opening the border region has enjoyed relatively high wage growth, widening regional wage differentials in the country (Hanson, 2004). However, the recent success of the border follows a period in which Mexico's poorer regions had been catching up. Chiquiar (2004) finds that from 1970 to 1985, the 15 years preceding Mexico's entry into the GATT, there was convergence in per capita GDP levels across Mexican states, and that after 1985 this process broke down. For the period 1985-2001, there is strong divergence in state per capita GDP levels. His results are reproduced in Figure 6. Mexico's globalization decade thus follows a period during which income differences between high-exposure states and low-exposure states had been closing.

Finally, it is important to note that exposure to globalization is not simply a proxy for the opportunity to migrate to the United States. Contrary to popular belief, migration to the United States is not especially common among residents of Mexican states on the U.S. border. Mexico's high migration states are in agricultural regions in central and western Mexico, which have dominated migration to the United States for most of the last century (Durand, Massey, and Zenteno, 2001). Most of these states have low exposure to FDI or to trade, as seen in Figures 7 and 8, which plot the fraction of the state population migrating to the United States over the period 1995-2000 against the share of FDI in state GDP or the share of imports in state GDP. This suggests that high exposure to globalization does not indicate high exposure to emigration.

Proximity to the United States explains part of regional differences in exposure to globalization, but it is clearly not the whole story. Other states have become more 
integrated into the global economy by virtue of having more skilled workers, better transportation infrastructure, or larger markets. These features, while present before globalization took hold in Mexico, are not exogenous. They reflect the ability of these states to develop economically, which may in turn reflect the quality of their legal or

political institutions or other historical factors. This suggests that my measure of exposure to globalization may proxy for institutional quality or other regional characteristics. Identifying the factors that determine regional variation in exposure to global markets, while beyond the scope if this paper, is important. Without this mapping, one cannot make policy recommendations. My findings will suggest that in Mexico regions more exposed to globalization have done better in terms of income growth. But the policy implications of this result are unclear as I leave unanswered the question of how one goes about increasing regional exposure.

\section{Empirical Methodology}

The empirical analysis involves comparing changes in income distribution during Mexico's globalization decade between two groups of states, states with high exposure to globalization and states with low exposure to globalization. In this section, I describe non-parametric and parametric approaches for making these comparisons.

\subsection{Estimating Counterfactual Income Densities}

Let $f(w \mid x, i, t)$ be the density of labor income, $w$, conditional on a set of observed characteristics, $x$, in region $i$ and time $t$. Define $h(x \mid i, t)$ as the density of observed characteristics among income earners in region $i$ and time $t$. For regions, $i=H$ indicates high exposure to globalization and $i=L$ indicates low exposure to globalization; for time 
periods, $t=00$ indicates the year 2000 and $t=90$ indicates the year 1990 . The observed density of labor income for individuals in $i$ at $t$ is,

$$
g(w \mid i, t)=\int f(w \mid x, i, t) h(x \mid i, t) d x
$$

Differences in $f(w \mid x, H, t)$ and $f(w \mid x, L, t)$ capture differences in returns to observable characteristics in regions with high versus low exposure to globalization; differences in $h(x \mid H, t)$ and $h(x \mid L, t)$ capture differences in the distribution of observed characteristics in high versus low-exposure regions.

To evaluate the change in income distributions across time and across regions, I would like to compare changes in $f(w \mid x, H, t)$ and $f(w \mid x, L, t)$, while holding the distribution of $x$ constant. However, in the data I do observe not these conditional densities, but the only marginal densities, $g(w \mid x, H, t)$ and $g(w \mid x, L, t)$. To evaluate these densities, I apply techniques from DiNardo, Fortin, and Lemieux (1996). First, consider the cross-time change in income distribution in the high-exposure region that is due to changes in returns to observable characteristics, which can be written as

$$
\int f(w \mid x, H, 00) h(x \mid H, 90) d x-\int f(w \mid x, H, 90) h(x \mid H, 90) d x
$$

Equation (2) evaluates the change in income distribution in high-exposure regions between 1990 and 2000, fixing the marginal density of observables to be that in highexposure regions in 1990. Rewrite equation (2) as

$$
\int\left[\theta^{H 90 \rightarrow H 00}-1\right] f(w \mid x, H, 90) h(x \mid H, 90) d x
$$

where

$$
\theta^{H 90 \rightarrow H 00}=\frac{f(w \mid x, H, 00)}{f(w \mid x, H, 90)}
$$


Equation (3) is simply the observed marginal income density in high-exposure regions in 1990, adjusted by a weighting function. Given an estimate of the weighting function in (4), it would be straightforward to apply a standard kernel density estimator to equation (3). The key, then, to estimating the change in income distribution that is due to changes in returns to observables is estimating the weighting function in (4).

Before turning to the weighting functions, consider the analog to equation (2) for regions with low exposure to globalization. The change in income distribution in lowexposure regions that is due to changes in returns to observables is

$$
\int f(w \mid x, L, 00) h(x \mid H, 90) d x-\int f(w \mid x, L, 90) h(x \mid H, 90) d x
$$

Equation (5) evaluates the change in income distribution in regions with low exposure to globalization between 1990 and 2000, again fixing the marginal density of observables to be that in high-exposure regions in 1990. To rewrite equation (5) in terms of the marginal density of income in high-exposure regions in 1990, apply the weights

$$
\theta^{H 90 \rightarrow L 00}=\frac{f(w \mid x, L, 00)}{f(w \mid x, H, 90)} \quad \text { and } \quad \theta^{H 90 \rightarrow L 90}=\frac{f(w \mid x, L, 90)}{f(w \mid x, H, 90)}
$$

which yields

$$
\int\left[\theta^{H 90 \rightarrow L 00}-\theta^{H 90 \rightarrow L 90}\right] f(w \mid x, H, 90) h(x \mid H, 90) d x
$$

As in estimating equation (3), estimating equation (7) comes down to applying the appropriate weighting function to a standard kernel density estimator.

The changes in conditional income densities in equations (2) and (5) reflect in part the impact of globalization and in part the impact of other aggregate shocks to the Mexican economy. The difference between these changes amounts to a difference-indifference estimator, which evaluates the change in returns to observables in regions with 
high exposure to globalization relative to the change in returns observables in regions with low exposure to globalization. Putting equations (3) and (7) together,

$$
\begin{aligned}
& \left(\int f(w \mid x, H, 00) h(x \mid H, 90) d x-\int f(w \mid x, H, 90) h(x \mid H, 90) d x\right)- \\
& \left(\int f(w \mid x, L, 00) h(x \mid H, 90) d x-\int f(w \mid x, L, 90) h(x \mid H, 90) d x\right)= \\
& \int\left\langle\left(\theta^{H 90 \rightarrow H 00}-1\right)-\left(\theta^{H 90 \rightarrow L O 0}-\theta^{H 90 \rightarrow L 90}\right)\right\rangle f(w \mid x, H, 90) h(x \mid H, 90) d x
\end{aligned}
$$

Equation (8) shows the 1990-to-2000 change income distribution in high-exposure regions relative to low-exposure regions, holding the distribution of observables constant. I use equation (8) to evaluate the impact of globalization on income distribution in Mexico. The choice of the high-exposure region in 1990 as the base case is purely arbitrary and should not affect the density difference. To check the robustness of the results, I will discuss estimates using other base cases.

To estimate the weighting functions in (4) and (6), I use Leibbrandt, Levinsohn, and McCrary's (2004) extension of the DiNardo, Fortin, and Lemieux (1996). Applying Bayes' Axiom to the weighting equations yields,

$$
\begin{aligned}
& \theta^{H 90 \rightarrow H 00}=\frac{f(w \mid x, H, 00)}{f(w \mid x, H, 90)}=\frac{\operatorname{Pr}(t=00, i=H) \mid w, x)}{1-\operatorname{Pr}(t=00, i=H) \mid w, x)} \frac{1-\operatorname{Pr}(t=00, i=H) \mid x)}{\operatorname{Pr}(t=00, i=H) \mid x)} \\
& \theta^{H 90 \rightarrow L 00}=\frac{f(w \mid x, L, 00)}{f(w \mid x, H, 90)}=\frac{\operatorname{Pr}(t=00, i=L) \mid w, x)}{1-\operatorname{Pr}(t=00, i=L) \mid w, x)} \frac{1-\operatorname{Pr}(t=00, i=L) \mid x)}{\operatorname{Pr}(t=00, i=L) \mid x)} \\
& \theta^{H 90 \rightarrow L 90}=\frac{f(w \mid x, L, 90)}{f(w \mid x, H, 90)}=\frac{\operatorname{Pr}(t=90, i=L) \mid w, x)}{1-\operatorname{Pr}(t=90, i=L) \mid w, x)} \frac{1-\operatorname{Pr}(t=90, i=L) \mid x)}{\operatorname{Pr}(t=90, i=L) \mid x)}
\end{aligned}
$$

Each weighting function is the product of odds ratios. Consider the first weight. The first ratio is the odds an individual is from a high-exposure region in 2000 (based on a 
sample of individuals from high-exposure regions in 1990 and 2000), conditional on observables, $x$, and labor income, $w$. The second ratio is the (inverse) odds an individual is from a high-exposure region in 2000 (again, based on a sample of individuals from high-exposure regions in 1990 and 2000), conditional on just on $x$. I can estimate the odds ratios by estimating two logit models. In each case, the dependent variable is a 0-1 variable on the outcome $i=H$ and $t=00$ (based on a sample of $i=H$ and $t=90$ or 00 ). For the first logit model, the regressors are $x$ and $w$; for the second, the regressor is $x$, alone. The other weights can be estimated analogously.

After estimating the weights, I apply them to a standard kernel density estimator to obtain estimates for the densities described by equations (3), (7), and (9). These estimates are for the difference in income densities, in the case of (3) and (7), and for the double difference in income densities, in the case of equation (9).

\subsection{A Parametric Analog}

The advantage of the approach described in section 3.1 is that it characterizes the difference in income across time periods and/or regions at all points in the distribution. The disadvantage is that there are no standard errors for these density differences. To examine the statistical significance of the results, I estimate a parametric analog to equation (8), which is simply a difference-in-difference wage equation.

I pool data on working age men in 1990 and 2000 from states with either high exposure or low exposure to globalization and then estimate the following regression,

$$
\ln w_{h s t}=\alpha_{s}+X_{h s t}\left(\beta_{1}+\beta_{2} Y 2000_{h t}+\beta_{3} H_{i g h} h s\right)+\phi * Y 2000_{h t} * H i g h_{h s}+\varepsilon_{h s t}
$$


where $w$ is labor market earnings, $X$ is a vector of observed characteristics, $Y 2000$ is a dummy variable for the year 2000, and High is a dummy variable for high-exposure states. The regression includes controls for state fixed effects and allows returns to observable characteristics to vary across regions and across time. The coefficient, $\varphi$, captures the differential change in earnings from 1990 to 2000 between states with highexposure and low-exposure to globalization.

Equation (10) is a standard difference-in-difference specification, which implies I estimate the mean differential in wage growth between low-exposure and high-exposure states. This approach ignores the possibility that the wage effect of being in a state with high exposure to globalization may not be uniform throughout the wage distribution. The results presented in the next section will provide evidence consistent with this possibility. A more elegant approach would be to estimate the regional differential in wage changes non-parametrically, as in the framework derived by Athey and Imbens (2003).

\subsection{Estimation Issues}

Several estimation issues merit attention. First, individuals self-select into regions. Individuals who have chosen to live in a state with high-exposure to globalization may have relatively high drive or ambition and may have moved to the state to take advantage of the opportunities globalization offers. Similarly, individuals who have chosen not to leave states with low-exposure to globalization may have relatively low drive or ambition. Given this pattern of selection, unobserved components of labor income would tend to be positive for individuals in high-exposure states and negative for individuals in low-exposure states. The estimation exercises in (9) and (10) would then be polluted by systematic differences in unobserved characteristics between regions. To 
avoid this problem, I categorize individuals by birth state and not by state of residence. In this way, I pick up earnings differences in where people live based on where they were born - a factor out of their control - and not on where they have chosen to reside - a factor in their control. Consistent with expectations, in 1990 83\% of those born in highexposure states still lived in those states, compared to only $73 \%$ of those born in lowexposure states. In 2000 , the figures were $82 \%$ and $70 \%$.

A second estimation issue is that individuals self-select into the labor force. This is partly due to age. Over time, young workers enter the labor force and older workers exit. To control for these movements, I limit the sample to the cohort of men who were 25 to 55 years old in 1990 (and 35 to 65 years old in 2000). Relatedly, if over the 1990's labor-market conditions improved by more in high-exposure states than in low-exposure states, high-exposure states may have registered a larger increase the fraction of lowability individuals participating in the labor force. Given this pattern of selection, unobserved components of labor income may have increased by less in high-exposure states and than in low-exposure states. ${ }^{8}$ To control for selection into the labor-force, I follow Lee (2004) and trim low-wage earners across the four samples (i.e., for $i=H, L$ and $t=90,00)$ such that the fraction included in the estimation is the same for each group.

A third estimation issue is that shocks other than globalization may have had differential impacts on regions with high versus low exposure to globalization. One such shock is the pesos crisis of 1995. After a bungled devaluation of the peso in 1994, Mexico chose to float its currency, which proceeded to plummet in value relative to the dollar. The ensuing increase in the peso value of dollar-denominated liabilities

\footnotetext{
${ }^{8}$ This suggests that selection into the labor force would work against selection into regions, in terms of the impact on unobserved components of earnings.
} 
contributed to a banking collapse and a severe macroeconomic contraction. It is hard to gauge whether the peso crisis would have hurt states with high exposure to globalization more or less than states with low exposure. On the one hand, high-exposure states are more specialized in the production of exports and the devaluation of the peso would have increased demand for their output. On the other hand, high-exposure states are better integrated into Mexico's financial markets and the banking collapse may have hurt them more. Other important shocks in the 1990's included a reform of Mexico's land tenure system in 1992, the ongoing privatization of state-owned enterprises and deregulation of industries, and the ruling party's loss of majority control in Mexico's congress in 1997. Again, it is hard to say whether these shocks would have helped or hurt high-exposure states more. The existence of these other shocks leaves the results subject to the caveat that factors other than globalization may have accounted for any differential change in income distribution across regions of the country. I return to this issue in section 5.

\section{Empirical Results}

The sample for the analysis is men aged 25 to 55 in 1990 or 35 to 65 in 2000 who were born in one of the seven Mexican states with high-exposure to globalization or in one of the ten Mexican states with low-exposure to globalization. The dependent variable is log average hourly labor earnings. ${ }^{9}$ I also discuss results using log total labor income as the dependent variable. Summary statistics are in Table 4.

\footnotetext{
${ }^{9}$ For Mexico, average hourly wages are calculated as monthly labor income/(4.5*hours worked last week); for the U.S., average hourly wages are calculated as annual labor income/(weeks worked last year*usual hours worked per week). Assuming individuals work all weeks of a month could bias wage estimates downwards. To avoid measurement error associated with implausibly low wage values or with top coding of earnings, I restrict the sample to be individuals with hourly wages between $\$ 0.05$ and $\$ 20$ (in 2000 dollars). This restriction is nearly identical to dropping the largest and smallest $0.5 \%$ of wage values.
} 


\subsection{Raw Income Distributions}

To provide a starting point for the analysis, consider the raw distributions of labor income in states with either high exposure or low exposure to globalization. Figure 9 shows kernel density estimates for hourly labor earnings in 1990 and 2000. In both years, the density for high-exposure states is shifted to the right compared to lowexposure states. Between 1990 and 2000, the difference between the wage densities in the two groups of states appears to widen. Higher wages in high-exposure states reflect in part the fact these states have a more highly educated labor force, as indicated by Table 4. Higher wages in high-exposure states may also reflect differences in the returns to observable characteristics across states in Mexico.

To see what these distributional differences imply about differences in the incidence of poverty between regions, Figure 10 shows the cumulative distribution for wages in high-exposure and low-exposure states in the two years. The vertical line in each graph shows the hourly wage needed to provide the minimum caloric intake for a family of four with one wage earner working the mean number of annual labor hours in that year. ${ }^{10}$ The peso value for the minimum caloric intake is from Cortes et al. (2003). The poverty wage line in Figure 10 is not meant to provide an accurate indicator of the fraction of individuals living in poverty. By focusing on labor income, I ignore other sources of household earnings. Government transfers, rental income, loans, in-kind receipts, and remittances also supplement family income, suggesting that the implied poverty wage threshold in Figure 10 is set too high - some families below this threshold

\footnotetext{
${ }^{10}$ In 1990 , the implied poverty cutoff for the hourly wage was $\$ 1.16$ in low-exposure regions and $\$ 1.25$ in highexposure regions (in 2000 US dollars), and in 2000, it was $\$ 1.13$ in low-exposure regions and $\$ 1.22$ in high-exposure regions. The poverty wage is lower in low-exposure regions because rural areas have lower prices for goods and because a higher fraction of the population in low-exposure regions lives in rural areas. The line shown in Figure 9 is that for the log poverty wage in low-exposure regions (in log terms the poverty wage in high-exposure and lowexposure regions is nearly the same).
} 
will receive enough income from other sources to allow them to afford a consumption level that is above the poverty cutoff. Still, the poverty wage is a useful benchmark for gauging the potential for a worker to sustain a family at above-poverty consumption levels on labor income alone (which is two-thirds of total income in Mexico).

In 1990, the fraction of workers earning less than the poverty cutoff wage in lowexposure regions (0.42) is twice that in high-exposure regions $(0.21)$. In 2000 , the difference is even larger, with the fraction of workers below the poverty wage at 0.49 in low-exposure regions and 0.22 in high-exposure regions. While it appears that poverty increased more rapidly in low-exposure regions, the results in Figure 10 are inconclusive. Since both the price of labor and the composition of labor is changing across regions and over time, we don't know whether the apparent increase in the relative incidence of poverty in low-exposure regions is due to a deterioration in the returns to observable characteristics or to change in the relative composition of the labor force. To separate these effects, I construct counterfactual income densities.

\subsection{Counterfactual Income Distributions}

To control for regional differences in the distribution of observable characteristics, I apply the weights in equation (9) to the kernel density for high-exposure states in 1990. This produces the two sets of densities in Figure 11. The first graph shows the actual income density in 1990 for high-exposure states and a counterfactual density that would obtain were workers in high-exposure states in 1990 paid according to the returns to observable characteristics in low-exposure states in 1990, or

$$
\int f(w \mid x, L, 90) h(x \mid H, 90) d x=\int \theta^{H 90 \rightarrow L 90} f(w \mid x, H, 90) h(x \mid H, 90) d x
$$


Since the distribution of observable characteristics is the same in the actual and counterfactual densities, comparing the two makes it possible to isolate the regional differences in income densities that are attributable to regional differences in returns to characteristics. In Figure 11, the density for high-exposure states in 1990 is again rightshifted relative to low-exposure states, though the regional difference in incomes is smaller than in Figure 9. Thus, even before Mexico's globalization decade, incomes were higher across the distribution in high-exposure states. These income differences may be due to high-exposure states historically having better infrastructure, being more specialized in the high-wage manufacturing sector, or being less specialized in the lowwage agricultural sector, among other factors (see Chiquiar, 2003, for a more complete discussion). This highlights the importance of controlling for initial income differences between states when examining changes in income distributions over time.

The second graph in Figure 11 shows income densities in 2000, evaluated based on the distribution of observable characteristics in high-exposure states 1990. For highexposure states, the resulting counterfactual density is what workers in high-exposure states in 2000 would earn were they to have the observable characteristics of workers in high-exposure states in 1990 , or

$$
\int f(w \mid x, H, 00) h(x \mid H, 90) d x=\int \theta^{H 90 \rightarrow H 00} f(w \mid x, H, 90) h(x \mid H, 90) d x
$$

For low-exposure states, the counterfactual is what workers in low-exposure states in 2000 would earn had they the characteristics of high-exposure states in 1990, or

$$
\int f(w \mid x, L, 00) h(x \mid H, 90) d x=\int \theta^{H 90 \rightarrow L 00} f(w \mid x, H, 90) h(x \mid H, 90) d x
$$

Comparing these counterfactuals isolates regional differences in income densities that are due to differences in returns to characteristics, rather than to the distribution of 
observables. As in 1990, the density for high-exposure states in 2000 is right-shifted relative to low-exposure states. Comparing the two years, it appears that differences in income densities between high-exposure and low-exposure states have increased over time, suggesting relative incomes have risen in the former.

To relate the counterfactual wage densities to poverty, Figure 12 shows the cumulative distribution analogues to the counterfactual wage kernels in Figure 11. The first graph in Figure 12 thus shows the cumulative density for wages in high-exposure and low-exposure states in 1990, based on the characteristics of workers in high-exposure regions in 1990. Comparing this graph to the first graph in Figure 10, we again see that the fraction of workers below the poverty wage is higher in low-exposure states $(0.32)$ than in high-exposure states (0.21). However, the difference in the incidence of wage poverty between the two groups of states in Figure $12(0.32-0.21=0.11)$ is considerably lower than in Figure $10(0.42-0.21=0.21)$. Holding constant the distribution of observable characteristics leaves the difference in cumulative distributions due to differences in returns to observables. Again, the apparent higher initial incidence of poverty in low-exposure states highlights the importance of controlling for initial conditions when comparing changes in income distributions.

The second graph in Figure 12 shows the cumulative density for wages in highexposure and low-exposure states in 2000 , based on the characteristics of workers in high-exposure regions in 1990. The fraction of workers earning less than the poverty wage is 0.40 in low-exposure states and 0.22 in high-exposure states, which again is a smaller difference $(0.40-0.22=0.18)$ than that for the actual wage distributions in Figure $10(0.49-0.22=0.27)$. Putting the 1990-to-2000 change in the incidence of wage poverty 
for low-exposure versus high-exposure states together yields a difference-in-difference estimate of $(0.40-0.32)-(0.22-0.21)=0.07$. During Mexico's globalization decade of the 1990 's, the incidence of wage poverty in low-exposure states appeared to increase relative to that in high-exposure states by approximately $7 \%$.

To explore these distributional changes in more detail, Figure 13 shows estimates of equation (2) - the 1990-to-2000 change in income densities in high-exposure states and of equation (5) - the 1990-to-2000 change in income densities in low-exposure states, where all densities are evaluated based on the distribution of observables in highexposure states in 1990 (as shown in equations (3) and (7)). In low-exposure states, there was a pronounced shift in mass from the upper half of the distribution to the lower half of the distribution. In high-exposure states, there was a modest shift in mass from the upper part of the distribution to the middle of the distribution. While labor incomes in the 1990's deteriorated in both regions, caused in part by Mexico's peso crisis in 1995, the deterioration was much less severe in states with high-exposure to globalization.

The change in regional relative incomes is seen more clearly in Figure 14, which shows an estimate of equation (8), the change in income density in high-exposure states relative to the change in income density in low-exposure states (evaluated for the distribution of observable characteristics in high-exposure states in 1990). It is clear that the income of high-exposure states has increased relative to the income of low-exposure states. This appears as shift in mass in the double density difference from the lower half of the distribution to the upper half of the distribution. During Mexico's globalization decade, individuals born in states with high-exposure to globalization appear to have done much better than individuals born in states with low-exposure to globalization. 
These results appear to be robust to changing the sample of states with either high-exposure or low-exposure to globalization. In unreported results, I experimented with dropping high-exposure states one at a time from the sample and re-estimating the income densities and with dropping low-exposure states one at a time and re-estimating the densities. Both sets of results are very similar to those reported.

\subsection{Additional Results}

Throughout the analysis, we have evaluated labor income densities fixing the distribution of observable characteristics to be those in states with high-exposure to globalization in 1990. This choice of the base case is arbitrary and should not affect the results. To examine the robustness of the findings, Figure 15 re-estimates the double difference in income densities in equation (8), evaluating all densities based on the distribution of observables in low-exposure states in 1990. Figure 15 is very similar to Figure 14, confirming that the choice of base case does not matter for the results.

The income densities shown so far are for average hourly labor earnings. If changes in wages affect individual labor supply, changes in hourly labor earnings may understate changes in total labor income. To see if this might be the case, Figure 16 estimates of the double density difference in equation (8), evaluated in terms of total labor income rather than average hourly labor income. Figure 16 is similar to Figure 14, suggesting that regional changes in the distribution of total labor income mirror regional changes in the distribution of hourly labor income.

In the results so far, I have included the full sample of workers from low-exposure and high-exposure states in 1990 and 2000. One concern is that the nature of selfselection into work varies across states or across time. If labor-force participation differs 
between low-exposure and high-exposure states, then cross-section comparisons in wage distributions may be contaminated by sample selection. If these differences are stable over time, they may not pose a problem for comparing changes in wage distributions. However, if labor-force participation changes differentially over time between lowexposure and high-exposure states, then sample selection may also contaminate the difference-in-difference analysis. For males with 9 or more years of education, laborforce participation rates are very similar in low-exposure and high-exposure states. For low-education males, labor-force participation rates are higher in high-exposure states and these differences appear to increase over time. This suggests the data are missing more low-wage workers in low-exposure state than in high-exposure states, which would tend to compress the estimated difference in wage distributions for the two groups of states. Further, since the relative fraction of missing low-wage workers in low-exposure states rises over time, my estimates would tend to understate the full extend of the change in relative wages between the two groups of states over time.

To deal with sample selection associated with labor-force participation, I apply Lee's (2004) technique for trimming observations to make them comparable across samples (which may vary by region, time, or some other dimension). The idea is that if both wages and labor-force participation are monotonically increasing in the unobserved component of wages, then it is possible to make two samples comparable in terms of the distribution of unobservables by trimming low-wage observations in the group that has higher labor force participation. We can't add low-wage workers who don't work into the sample in the low-labor-force participation group, but we can drop from the sample low-wage workers in the high-labor-force participation group (who presumably wouldn't 
work if they were to be placed in the other group). I trim low-wage workers from the high-labor-force participation group until I obtain two samples that are identical in terms of the fraction of wage earners included. Figures 17 and 18 redo Figures 13 and 14 applying Lee's trimming procedure. It remains the case that wages deteriorate by more in low-exposure states. Income in high-exposure states increases relative to income in low-exposure states, which appears as shift in mass in the double density difference from the lower half of the distribution to the upper half of the distribution. This is further evidence that during Mexico's globalization decade individuals born in states with highexposure to globalization have done relatively well in terms of their labor earnings.

\subsection{Parametric Results}

While the non-parametric results a strong increase in relative incomes in states with high exposure to globalization they give no sense of the statistical precision of these estimates. As a check on the statistical significance of the results, Table 5 shows estimation results for equation (10). The dependent variable is log average hourly labor earnings. The regressors are dummy variables for educational attainment, a quadratic in age, a dummy variable for the year 2000 and its interaction with the age and education variables, a dummy variable for having been born in a state with high-exposure to globalization and its interaction with the age and education variables, dummy variables for the state, and the interaction of the year 2000 and high-exposure-to-globalization dummy variables. This last variable captures the differential change in wage growth in high-exposure states relative to low-exposure states. Standard errors are adjusted for correlation across observations within the same state. 
Panel (a) of Table 5 shows that during the 1990's the cohort of individuals born in states with high exposure to globalization enjoyed labor earnings growth that was 7.9 to $9.2 \log$ points higher than earnings growth for individuals born in low-exposure states. These coefficients are precisely estimated. This is consistent with the counterfactual density estimates and again suggests than individuals in high-exposure states enjoyed higher growth in labor income that individuals in low-exposure states. The second two columns of Table 5 show results where the year200/high-exposure interaction is interacted with a dummy variable for an individual having completed a secondary education. This term allows relative earnings growth to be larger for more-educated workers. The interaction term is negative, but imprecisely estimated.

Panel (b) of Table 5 redoes the estimation, trimming observations across the samples to account for possible self-selection into work. Estimated relative wage growth for high-exposure states is higher using this estimation method, with individuals born in high-exposure states enjoying labor earnings growth 9.0 to $10.9 \log$ points higher than for individuals born in low-exposure states. In the second two columns, the interaction between the year200/high-exposure interaction and the dummy variable for secondary education is negative, precisely estimated, and similar in absolute value to the main effect (the year 2000/high-exposure interaction). This suggests that on average most of the relative wage growth for individuals born in high-exposure states went to individuals with low levels of schooling. The income gains in moving from low-exposure to highexposure states appear to be largest for low-wage workers. 


\section{Conclusion}

In this paper, I examine the change in the distribution of labor income across regions of Mexico during the country's decade of globalization in the 1990's. I focus the analysis on men born in states with either high-exposure to globalization or in states with low-exposure to globalization, as measured by the share of foreign direct investment, imports, and export assembly in state GDP during the 1990's. Mexican states with high exposure to globalization are located along the U.S. border and in the relatively skillabundant center-west region of the country; states with low exposure to globalization are primarily located in more rural southern Mexico. I exclude from the analysis individuals born in states with intermediate exposure to globalization.

Controlling for regional differences in the distribution of observable characteristics and for initial differences in regional incomes, the distribution of labor income in high-exposure states shifted to the right relative to the distribution of income in low-exposure states. This change in regional relative incomes was the result of a shift in mass in the income distribution of low-exposure states from upper-middle income earners to lower income earners. Labor income in low-exposure states fell relative to highexposure states by $8-12 \%$ and the incidence of wage poverty (the fraction of wage earners whose labor income would not sustain a family of four at above-poverty consumption levels) increased in low-exposure states relative to high-exposure states by $7 \%$.

There are several possible interpretations of these results. One is that trade and investment liberalization raised incomes in states with high exposure to the global economy relative to states with low exposure to the global economy. However, trade and investment reforms were by no means the only shocks to the Mexican economy during 
the 1990's. The Mexican peso crisis in 1995 was another important event. The results are also consistent with states that were more integrated into the global markets being better able to weather the large devaluation of the peso, the banking crisis, and the contraction in economic activity that occurred in Mexico during the mid 1990's. Highexposure states are relatively specialized in export production and would potentially benefit from a depreciation of the currency.

Other policy changes, such as the privatization and deregulation of Mexican industry or the reform of Mexico's land-tenure system, may also have had differential regional impacts in Mexico. Privatization and deregulation appeared to weaken Mexico's unions and lower wage premiums enjoyed by workers in these sectors (Fairris, 2003). Since more heavily unionized industries are concentrated in Mexico's north and center, and relatively absent in Mexico's south (Chiquiar, 2003), we might expect a loss in union power to lower relatives incomes in states with higher exposure to globalization, contrary to what we observe in the data. The reform of Mexico's land-tenure system allowed individuals to sell agricultural land previously held in cooperative ownership. In principal we might expect this opportunity to raise relative incomes in rural southern Mexico, where agriculture accounts for a relatively high share of employment and output. Again, this is contrary to what we observe in the data.

Another possibility is that income growth in high-exposure states merely reflects continuing trends unrelated to globalization. This also does not appear to be the case. As seen in Figure 6, poorer states, which includes seven of the ten states with low-exposure to globalization, had faster growth in per capita income than richer states, which includes six of the seven high-exposure states. The process of income convergence in Mexico 
came to a halt in 1985 , coinciding with the onset of trade liberalization. Since 1985, regional incomes have diverged in the country. The pattern of income growth I uncover does not appear to have been evident in the early 1980s or before.

A brief review of Mexico's other policy reforms during the 1990's does not suggest any obvious reason why they should account for the observed increase in relative incomes in states with high-exposure to globalization. Still, it is important to be cautious about ascribing shifts in regional relative incomes to specific policy changes. In the end, we can only say that I find suggestive evidence that globalization has increased relative incomes in Mexican states that are more exposed to global markets. 


\section{References}

Ariola, Jim and Chinhui Juhn. 2003. "Wage Inequality in Post-Reform Mexico." Mimeo, University of Houston.

Athey, Susan and Guido Imbens. 2003. "Identification and Inference in Nonlinear Difference-In-Difference Models," mimeo, Stanford University.

Attanasio, Orazio, Pinelopi Goldberg and Nina Pavcnik. 2004. "Trade Reforms and Wage Inequality in Colombia." Journal of Development Economics, 74: 331-366.

Behrman, Jere, Nancy Birdsall, and Miguel Szekely. 2003. "Economic Policy and Wage Differentials in Latin America." Mimeo, University of Pennsylvania.

Chiquiar, Daniel. 2003. Essays on the Regional Implications of Globalization: The Case of Mexico. Ph.D. Dissertation, University of California, San Diego.

Chiquiar, Daniel. 2004. "Why Mexico's Regional Income Convergence Broke Down." Journal of Development Economics, forthcoming.

Cortes, Fernando, Daniel Hernandez, Enrique Hernandez Laos, Miguel Szekely, and Hadid Vera Llamas. 2003. "Evolucion y Caracteristicas de la Pobreza en Mexico en la Ultima Decada del Siglo XX.” Economia Mexicana, XII(2): 295-328.

Cragg, Michael I. and Mario Epelbaum. 1996. "The Premium for Skills in LDCs: Evidence from Mexico.” Journal of Development Economics 51(1): 99-116.

Currie, Janet, and Ann Harrison. 1997. "Trade Reform and Labor Market Adjustment in Morocco." Journal of Labor Economics, 15: S44-71.

Deaton, Angus and J. Muellbauer. 1980. Economics and Consumer Behavior. Cambridge: Cambridge University Press.

DiNardo, John, M. Fortin, and Thomas Lemieux. 1996. "Labor Market Institutions and the Distribution of Wages, 1973-1992: A Semiparametric Approach." Econometrica 64(5): 1001-1044.

Durand, Jorge, Douglas S. Massey, and Rene M. Zenteno. 2001. "Mexican Immigration in the United States." Latin American Research Review 36(1): 107-127.

Fairris, David H. 2003. Unions and Wage Inequality in Mexico. Industrial and Labor Relations Review, 56(3): 481-97.

Feliciano, Zadia. 2001. "Workers and Trade Liberalization: The Impact of Trade Reforms in Mexico on Wages and Employment." Industrial and Labor Relations Review 55(1): 95115. 
Feenstra, Robert C. 1998. "Integration of Trade and Disintegration of Production in the Global Economy." Journal of Economic Perspectives, 12: 31-50.

Feenstra, Robert C., and Gordon H. Hanson. 1997. "Foreign Direct Investment and Relative Wages: Evidence from Mexico's Maquiladoras." Journal of International Economics, 42(3-4): 371-394.

Feenstra, Robert C. and Gordon H. Hanson. 2003. "Global Production and Inequality: A Survey of Trade and Wages," in James Harrigan, ed., Handbook of International Trade, Basil Blackwell.

Feenstra, Robert C. and Gordon H. Hanson. 1999. "Productivity Measurement and the Impact of Trade and Technology on Wages: Estimates for the U.S., 1972-1990," Quarterly Journal of Economics, August, 114:907-940.

Freeman, Richard B., "Are Your Wages Set in Beijing?" Journal of Economic Perspectives, 9(1995):15-32.

Freeman, Richard B. 2003. "Trade Wars: The Exaggerated Impact of Trade in Economic Debate.” NBER Working Paper no. 10000.

Goldberg, Pinelopi, and Nina Pavcnik. 2004. "Trade, Inequality, and Poverty: What Do We Know? Evidence from Recent Trade Liberalization Episodes in Developing Countries." NBER Working Paper no. 10593.

Hansen, Niles. 1981. The Border Economy: Regional Development in the Southwest. Austin: University of Texas Press.

Hanson, Gordon. 2004. "What Has Happened to Wages in Mexico since NAFTA?", in Toni Estevadeordal, Dani Rodrik, Alan Taylor, Andres Velasco, eds., FTAA and Beyond: Prospects for Integration in the Americas, Cambridge: Harvard University Press.

Hanson, Gordon H. and Ann E. Harrison. 1999. Trade, Technology, and Wage Inequality in Mexico. Industrial and Labor Relations Review 52(2): 271-288.

Hsieh, Chang-Tai. 2003. "The Impact of Outsourcing to China on Hong Kong's Labor Market," Mimeo, UC Berkeley.

Katz, Lawrence F. and David Autor, "Changes in the Wage Structure and Earnings Inequality," in Orley Ashenfelter and David Card, eds., Handbook of Labor Economics, Vol. 3A, Amsterdam: Elsevier Science, 1999, 1463-1555.

Lee, David. 2004. "Trimming for Bounds on Treatment Effects with Missing Outcomes." Mimeo, UC Berkeley. 
Leibbrandt, Murray, James Levinsohn, and Justin McCrary. 2004. "Incomes in South Africa since the Fall of Apartheid." Mimeo, University of Michigan.

Nicita, Alessandro. 2004. "Who Benefited from Trade Liberalization in Mexico? Measuring the Effects on Household Welfare." World Bank Policy Research Working Paper No. 3265.

Pavcnik, Nina. 2003. "What Explains Skill Upgrading in Less Developed Countries?" Journal of Development Economics, 71: 311-328.

Revenga, Anna L. 1997. Employment and Wage Effects of Trade Liberalization: The Case of Mexican Manufacturing. Journal of Labor Economics 15(3): S20-43.

Richardson, J. David. 1995. "Income Inequality and Trade: How to Think, What to Conclude." Journal of Economic Perspectives 9: 33-56.

Robertson, Raymond. 2000. "Wage Shocks and North American Labor Market Integration." American Economic Review 90(4): 742-764.

Winters, L. Alan, Neil McCulloch, and Andrew McKay. 2004. "Trade Liberalization and Poverty: The Evidence So Far." Journal of Economic Literature 42: 72-115. 
Table 1: Percent of Mexico's Population with Per Capita Income below Threshold Needed to Achieve Minimum Caloric Intake

\begin{tabular}{lccccc} 
Area & 1992 & 1994 & 1996 & 1998 & 2000 \\
\hline $\begin{array}{l}\text { Urban } \\
\text { Households }\end{array}$ & 10.2 & 7.2 & 20.1 & 16.4 & 9.8 \\
& & & & & \\
$\begin{array}{l}\text { Rural } \\
\text { Households }\end{array}$ & 29.5 & 30 & 43.3 & 43.8 & 34.1 \\
\hline
\end{tabular}

Source: Cortés, et.al (2003).

Table 2: Correlation Matrix for Measures of Exposure to Globalization Across Mexican States in the 1990's

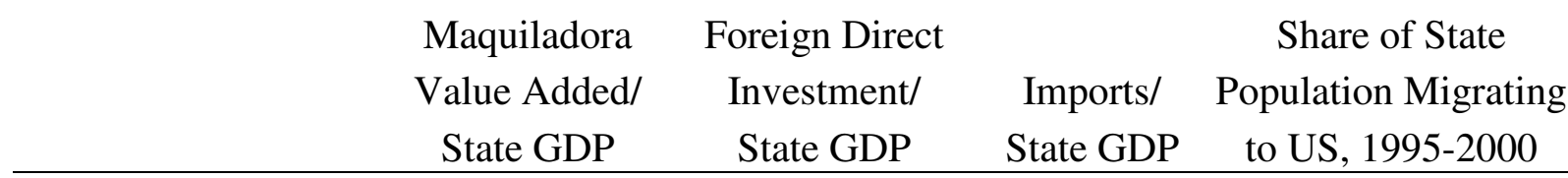

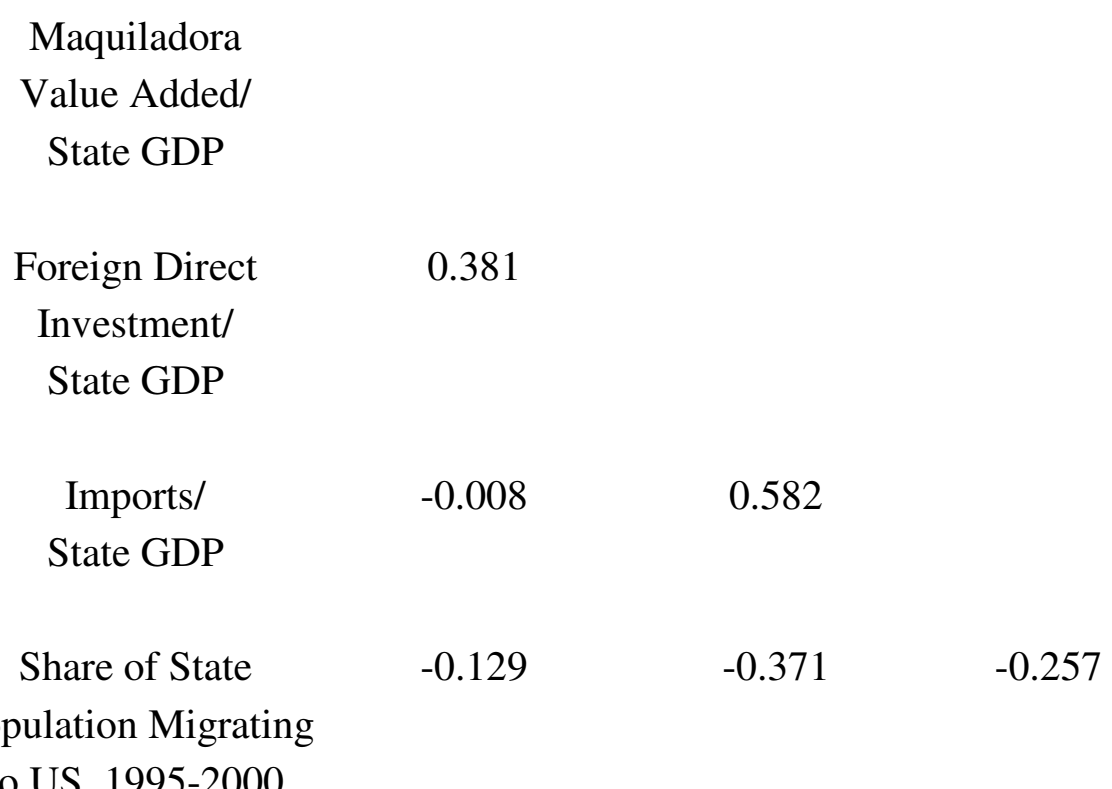

to US, 1995-2000

Notes: Shares of state GDP (maquiladora value added, foreign direct investment, imports) are averages over the period 1993-1999. Correlations are weighted by state share of the national population (averaged over 1990 to 2000). 
Table 3: Categorizing Mexican States by Exposure to Globalization in the 1990's

\begin{tabular}{|c|c|c|c|c|c|}
\hline & \multirow[b]{2}{*}{ State } & \multirow{2}{*}{$\begin{array}{c}\text { Average } \\
\text { Rank }\end{array}$} & \multicolumn{3}{|c|}{ Share of State GDP } \\
\hline & & & FDI & Imports & Maquiladoras \\
\hline & Baja California & 30 & 0.070 & 0.018 & 0.246 \\
\hline High & Chihuahua & 28 & 0.030 & 0.018 & 0.214 \\
\hline Exposure & Nuevo Leon & 28 & 0.039 & 0.027 & 0.023 \\
\hline to & Sonora & 27 & 0.015 & 0.034 & 0.088 \\
\hline \multirow[t]{8}{*}{ Globalization } & Jalisco & 25 & 0.018 & 0.027 & 0.029 \\
\hline & Tamaulipas & 25 & 0.035 & 0.013 & 0.181 \\
\hline & Aguascalientes & 25 & 0.015 & 0.014 & 0.046 \\
\hline & DF & 22 & 0.055 & 0.058 & 0.000 \\
\hline & Coahuila & 22 & 0.011 & 0.014 & 0.077 \\
\hline & Yucatan & 21 & 0.005 & 0.023 & 0.031 \\
\hline & Puebla & 19 & 0.009 & 0.015 & 0.015 \\
\hline & Baja California Sur & 19 & 0.032 & 0.011 & 0.008 \\
\hline Intermediate & San Luis Potosi & 18 & 0.028 & 0.011 & 0.013 \\
\hline \multirow[t]{10}{*}{ States } & Guanajuato & 18 & 0.009 & 0.014 & 0.008 \\
\hline & Sinaloa & 17 & 0.005 & 0.027 & 0.001 \\
\hline & Tlaxcala & 17 & 0.019 & 0.010 & 0.020 \\
\hline & Queretaro & 16 & 0.013 & 0.011 & 0.011 \\
\hline & Durango & 16 & 0.001 & 0.012 & 0.035 \\
\hline & Tabasco & 16 & 0.010 & 0.017 & 0.000 \\
\hline & Morelos & 15 & 0.024 & 0.010 & 0.005 \\
\hline & Mexico & 15 & 0.031 & 0.008 & 0.004 \\
\hline & Michoacan & 15 & 0.000 & 0.016 & 0.000 \\
\hline & Zacatecas & 15 & 0.003 & 0.013 & 0.008 \\
\hline Low & Quintana Roo & 12 & 0.006 & 0.011 & 0.000 \\
\hline Exposure & Nayarit & 10 & 0.006 & 0.011 & 0.000 \\
\hline to & Colima & 9 & 0.002 & 0.014 & 0.000 \\
\hline \multirow[t]{6}{*}{ Globalization } & Guerrero & 9 & 0.004 & 0.007 & 0.002 \\
\hline & Veracruz & 8 & -0.004 & 0.012 & 0.000 \\
\hline & Chiapas & 6 & 0.000 & 0.011 & 0.000 \\
\hline & Campeche & 5 & 0.001 & 0.008 & 0.000 \\
\hline & Hidalgo & 4 & 0.000 & 0.007 & 0.000 \\
\hline & Oaxaca & 2 & 0.000 & 0.005 & 0.000 \\
\hline
\end{tabular}

Notes: Shares of state GDP (foreign direct investment, imports, maquiladora value added) are averages over the period 1993-1999. 


\section{Table 4: Summary Statistics}

\begin{tabular}{|c|c|c|c|c|c|c|}
\hline \multirow[t]{2}{*}{ Year } & & \multirow[t]{2}{*}{ Variable } & \multicolumn{2}{|c|}{$\begin{array}{l}\text { High Exposure to } \\
\text { Globalization }\end{array}$} & \multicolumn{2}{|c|}{$\begin{array}{c}\text { Low Exposure to } \\
\text { Globalization }\end{array}$} \\
\hline & & & Mean & St. Dev. & Mean & St. Dev. \\
\hline \multirow[t]{9}{*}{1990} & & Age & 33.6 & 5.9 & 33.9 & 5.9 \\
\hline & High Grade & 0 & 0.055 & 0.229 & 0.132 & 0.338 \\
\hline & of & 1 to 5 & 0.185 & 0.388 & 0.285 & 0.452 \\
\hline & Schooling & 6 to 8 & 0.273 & 0.445 & 0.255 & 0.436 \\
\hline & Completed & 9 to 11 & 0.208 & 0.406 & 0.141 & 0.348 \\
\hline & & 12 to 15 & 0.139 & 0.346 & 0.100 & 0.300 \\
\hline & & $16+$ & 0.140 & 0.347 & 0.087 & 0.282 \\
\hline & & Wage & 2.590 & 2.610 & 1.781 & 2.073 \\
\hline & & $\mathrm{N}$ & 13,771 & & 19,352 & \\
\hline \multirow[t]{9}{*}{2000} & & Age & 43.0 & 5.7 & 43.2 & 5.8 \\
\hline & High Grade & 0 & 0.036 & 0.187 & 0.093 & 0.290 \\
\hline & of & 1 to 5 & 0.178 & 0.383 & 0.255 & 0.436 \\
\hline & Schooling & 6 to 8 & 0.259 & 0.438 & 0.259 & 0.438 \\
\hline & Completed & 9 to 11 & 0.207 & 0.405 & 0.157 & 0.364 \\
\hline & & 12 to 15 & 0.142 & 0.349 & 0.109 & 0.312 \\
\hline & & $16+$ & 0.177 & 0.382 & 0.128 & 0.334 \\
\hline & & Wage & 2.656 & 2.798 & 1.674 & 1.965 \\
\hline & & $\mathrm{N}$ & 11,807 & & 17,967 & \\
\hline
\end{tabular}

Note: Sample is men with positive labor earnings aged 25-55 in 1990 or 35-65 in 2000 born in states with either high-exposure to globalization or low-exposure to globalization. Wages are average hourly levels in 2000 U.S. dollars. 
Table 5: Regression Results

\begin{tabular}{ccccc}
\hline & All & $\begin{array}{c}\text { Workers w/ } \\
\text { 20-80 Hour } \\
\text { Work Week }\end{array}$ & $\begin{array}{c}\text { All } \\
\text { Workers }\end{array}$ & $\begin{array}{c}\text { Workers w/ } \\
\text { 20-80 Hour } \\
\text { Work Week }\end{array}$ \\
\hline \multicolumn{5}{c}{ (a) Full Sample of Workers } \\
Year 2000*High Exposure & 0.092 & 0.079 & 0.115 & 0.116 \\
& $(0.039)$ & $(0.033)$ & $(0.053)$ & $(0.050)$ \\
Year 2000*High & & & & \\
Exposure* & & & -0.050 & -0.079 \\
Secondary Education & & & $(0.042)$ & $(0.046)$ \\
R & 0.337 & 0.373 & 0.337 & 0.373 \\
$\mathrm{~N}$ & 45,012 & 42,298 & 45,012 & 42,298 \\
\hline
\end{tabular}

(b) Trimmed Sample to Account for Sample Selection

\begin{tabular}{ccccc} 
Year 2000*High Exposure & 0.109 & 0.090 & 0.159 & 0.153 \\
& $(0.029)$ & $(0.025)$ & $(0.040)$ & $(0.039)$ \\
& & & & \\
Year 2000*High Exposure & & & -0.106 & -0.130 \\
*Secondary Education & & & $(0.031)$ & $(0.034)$ \\
R & 0.380 & 0.417 & 0.380 & 0.418 \\
$\mathrm{~N}$ & 42,711 & 40,224 & 42,711 & 40,224 \\
\hline
\end{tabular}

Notes: The dependent variable is log average hourly labor earnings. In columns 1 and 3 , the sample is non-self-employed males born in states with high exposure to globalization or states with low exposure to globalization; in columns 2 and 4, the sample includes only the non-self-employed who report working 20-80 hours a week. Other regressors (quadratic in age, dummies for year of education, and their interactions with year 2000 dummy and with High Exposure dummy; year 2000 dummy variable; state dummy variables) are not shown. Standard errors are in parentheses and are adjusted for correlation across observations within birth states. In panel (a), the sample is working males in all states and time periods; in panel (b), I trim low-wage workers in high-laborforce-participation state/year groups until the fraction of wage-earners is the same in lowexposure and high-exposure states and in the two years. 


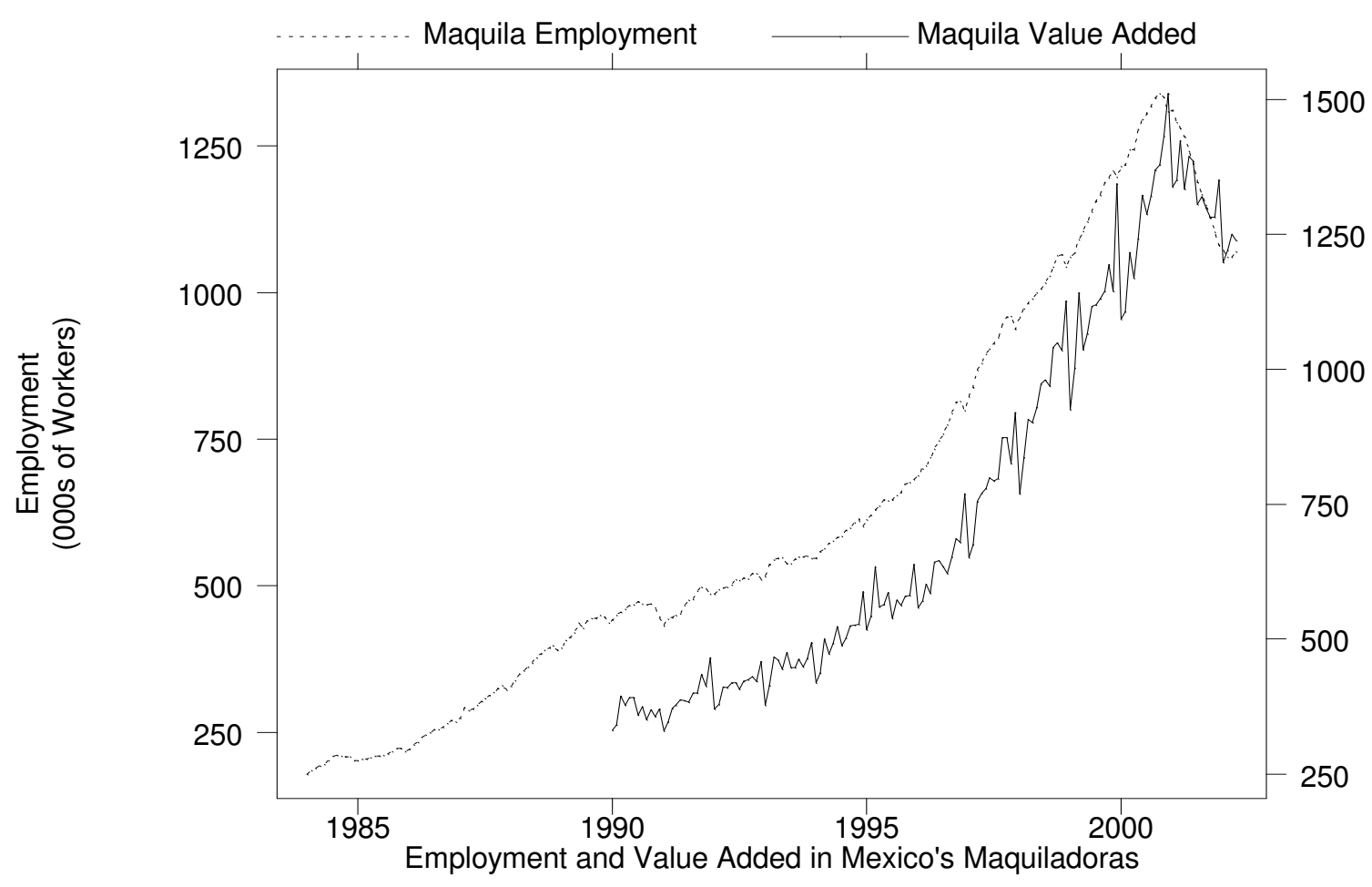

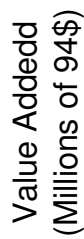

Figure 1

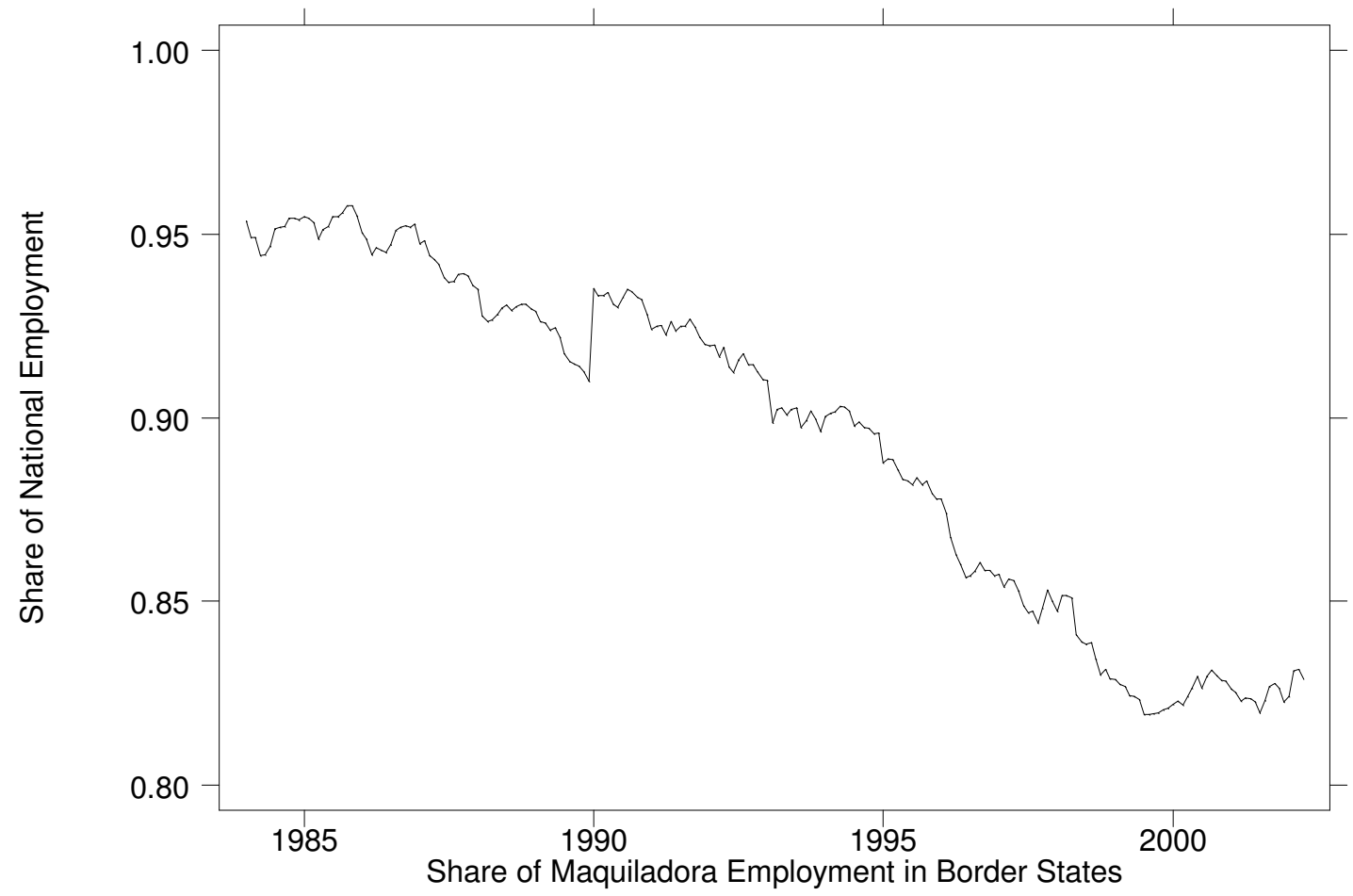

Figure 2 


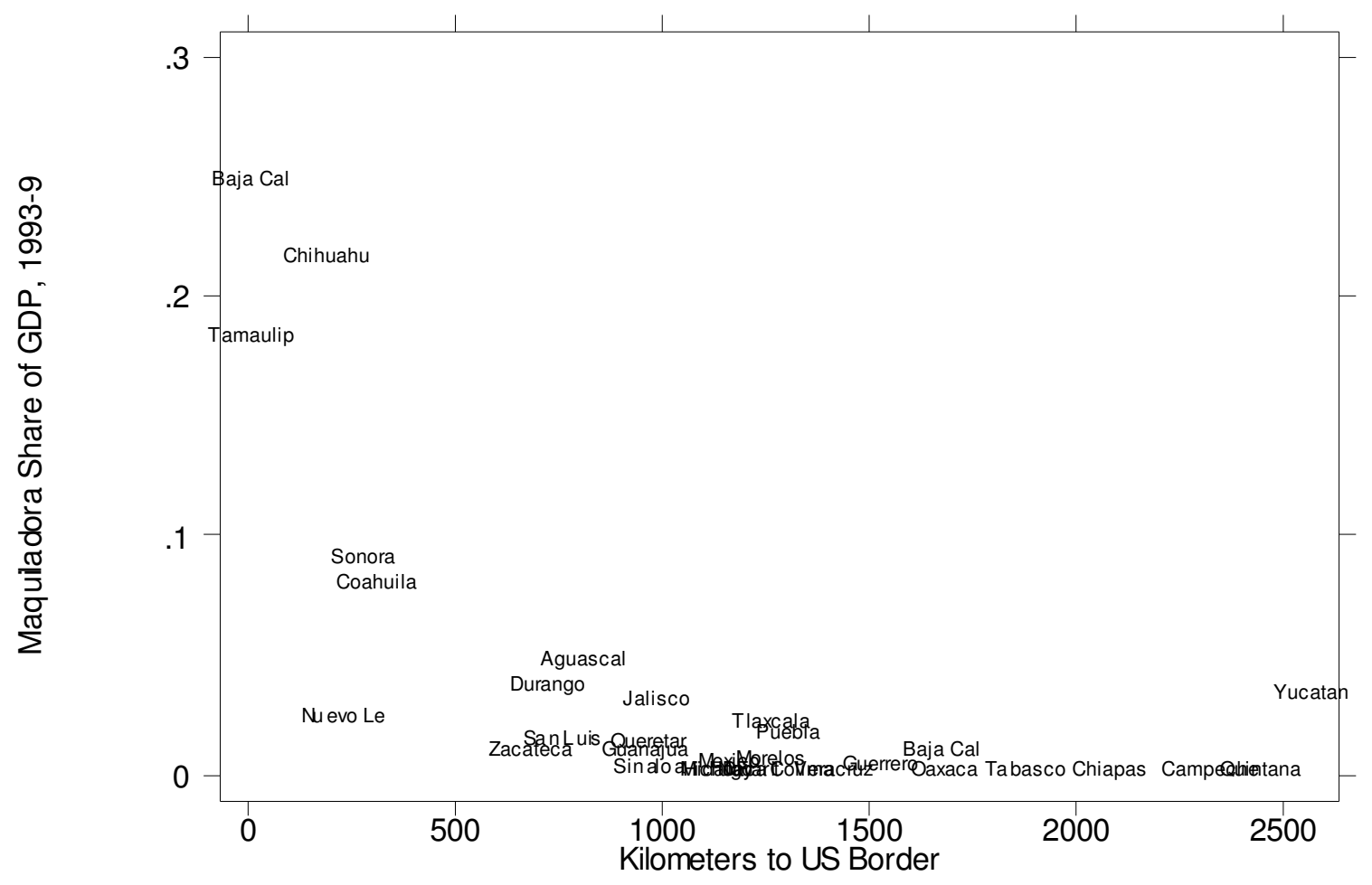

Figure 3

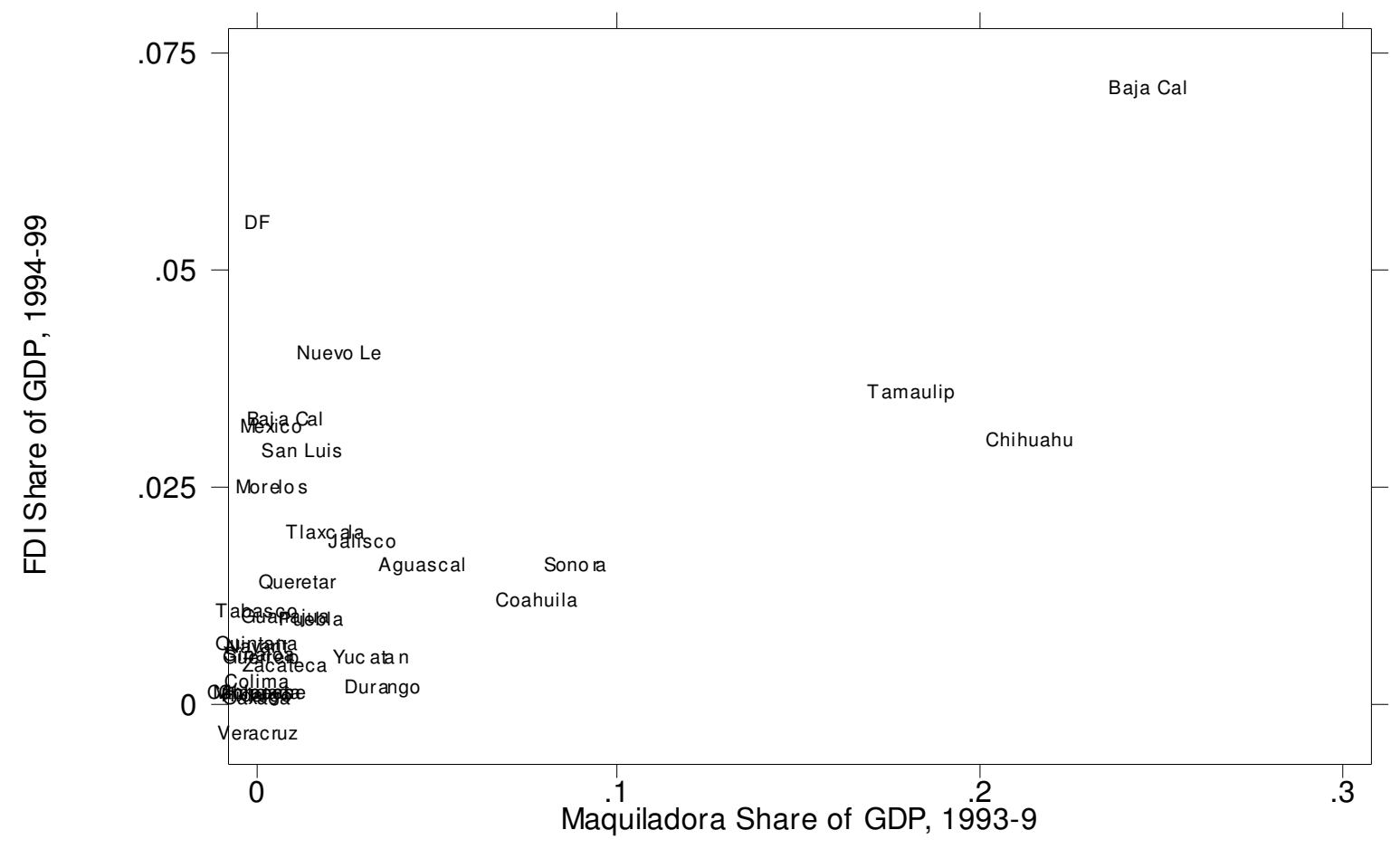

Figure 4 


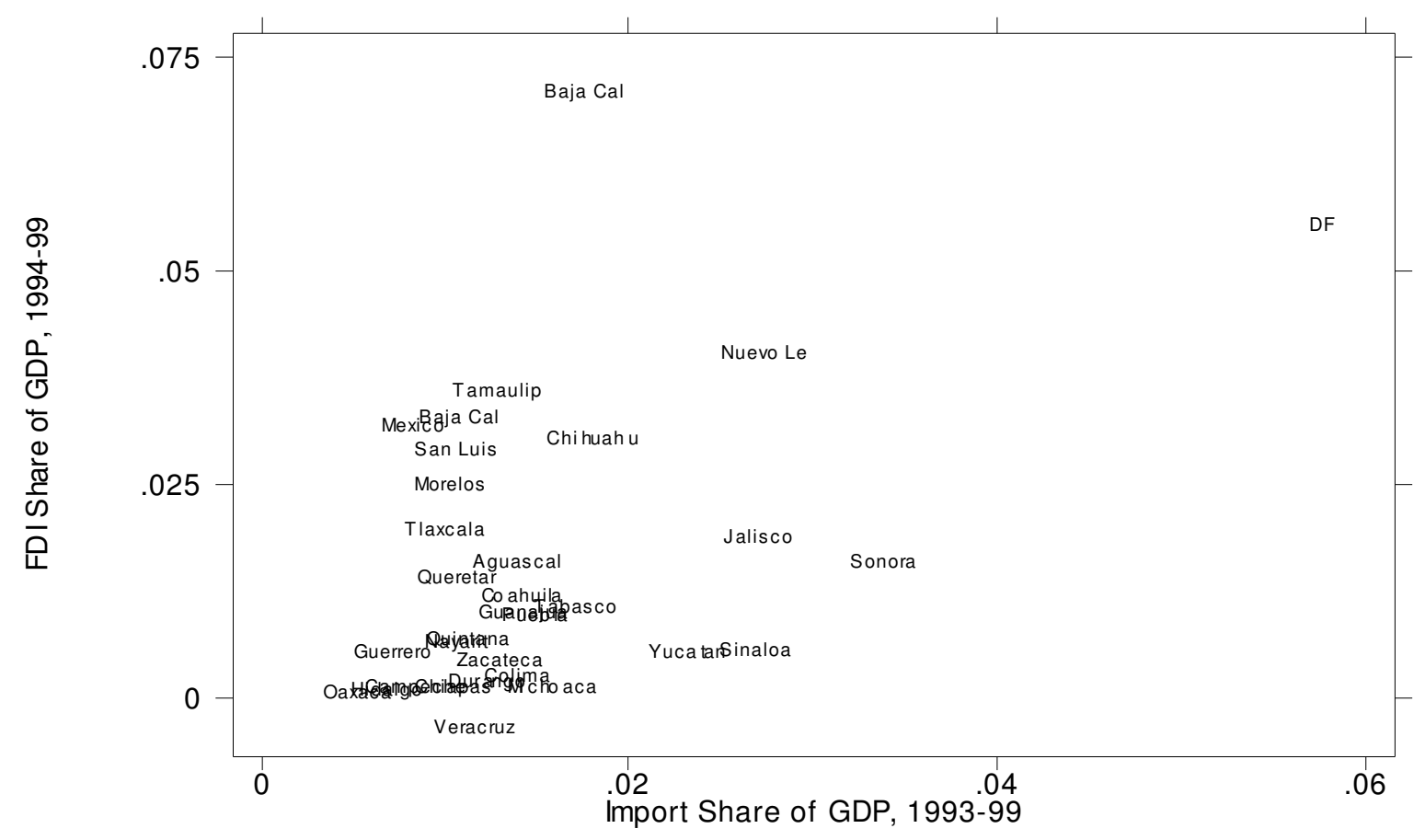

Figure 5 

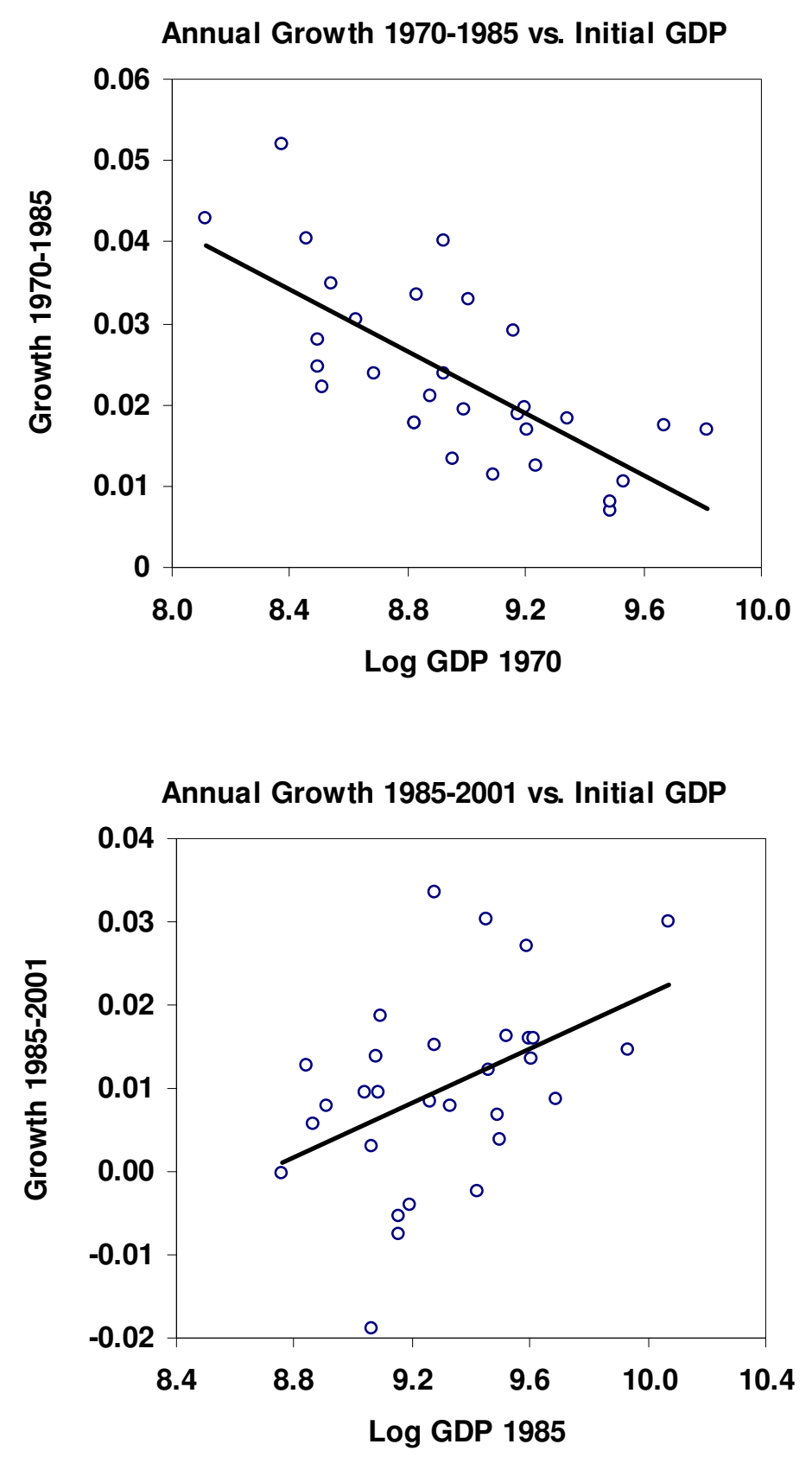

Figure 6: Growth in Log GDP across Mexican States, 1970-2001 


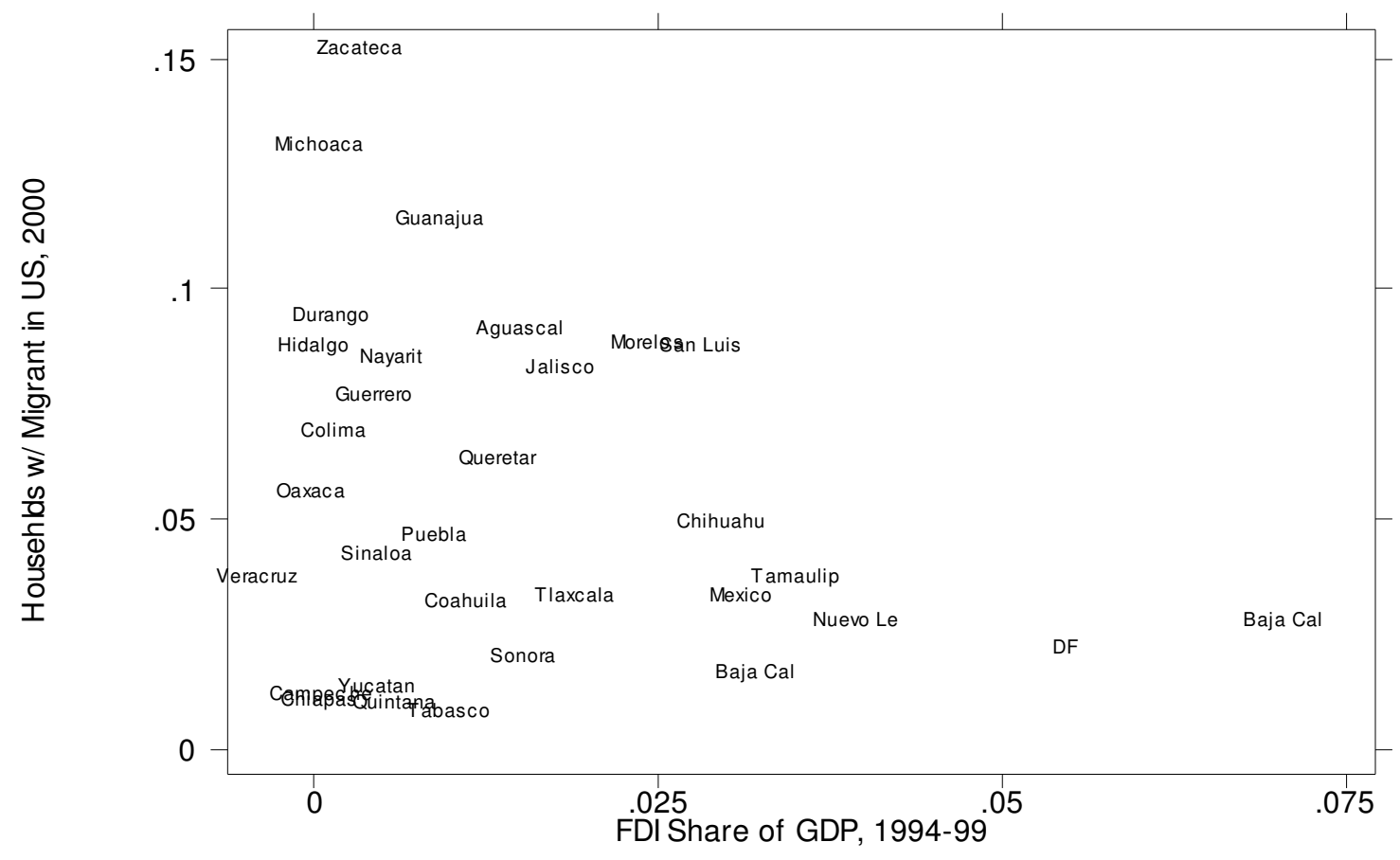

Figure 7

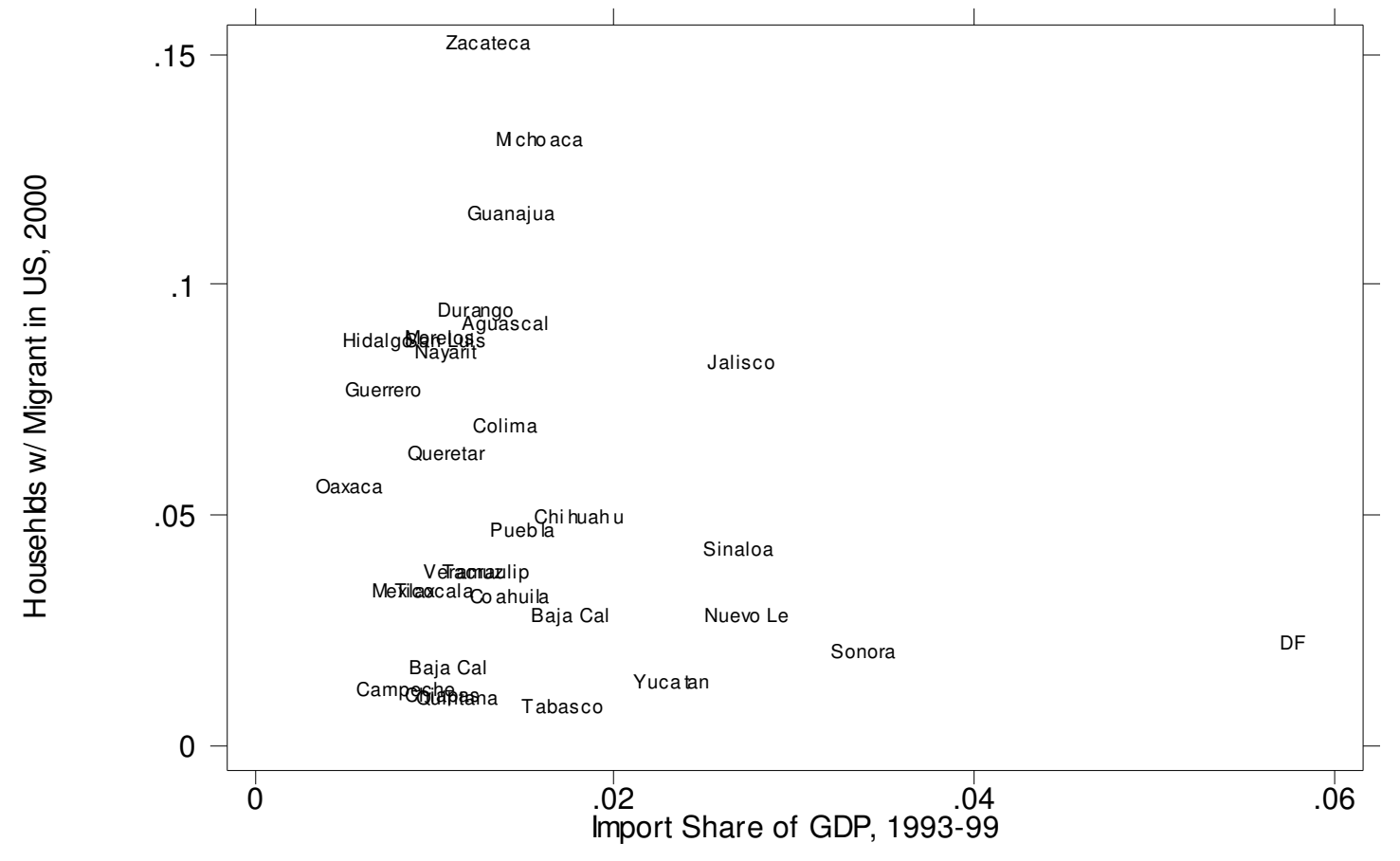

Figure 8 
Figure 9: Density of Hourly Labor Income in States with

High Exposure and Low Exposure to Globalization, 1990 and 2000
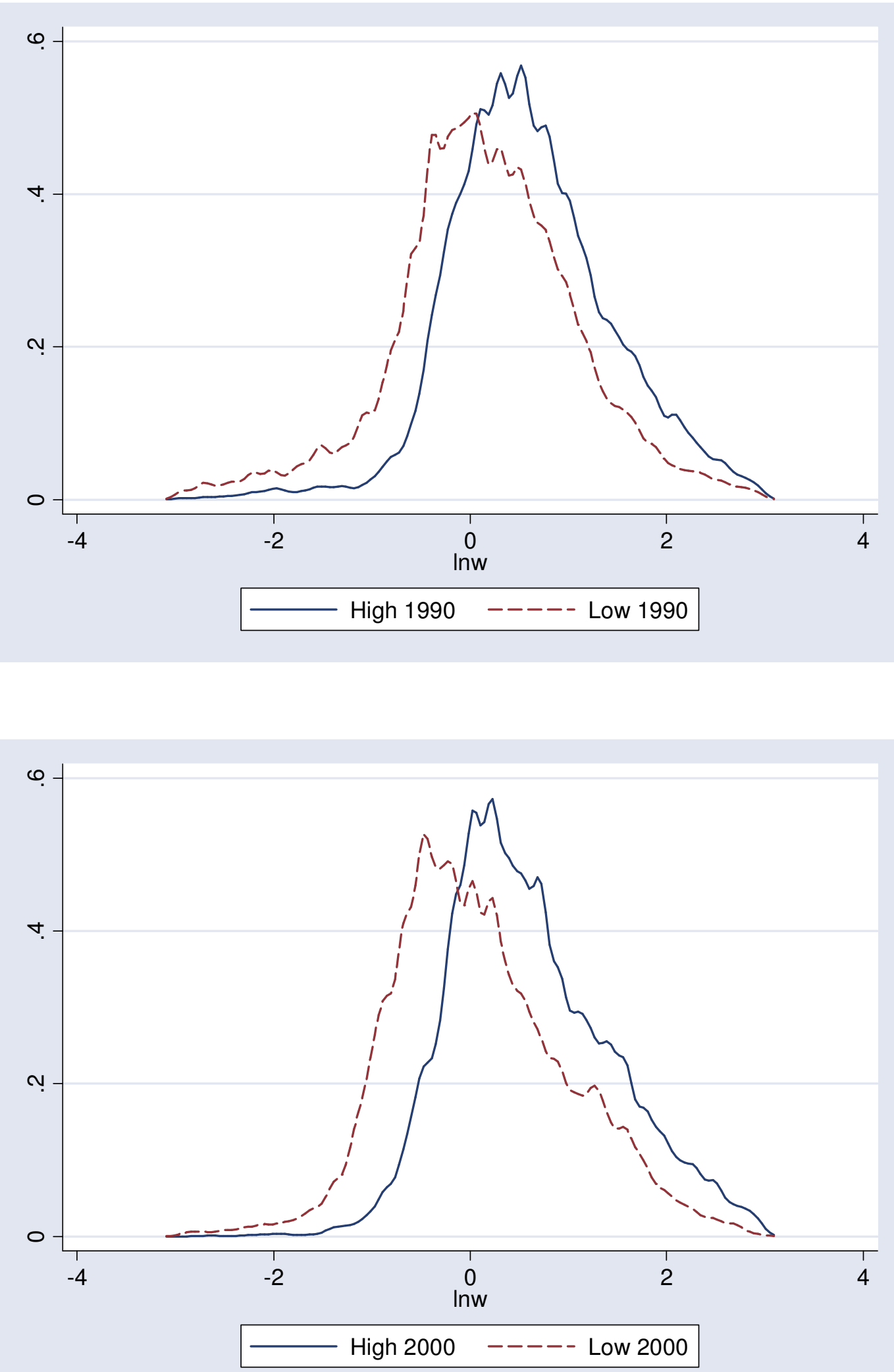
Figure 10: Cumulative Distribution of Hourly Labor Income in States with High Exposure and Low Exposure to Globalization, 1990 and 200
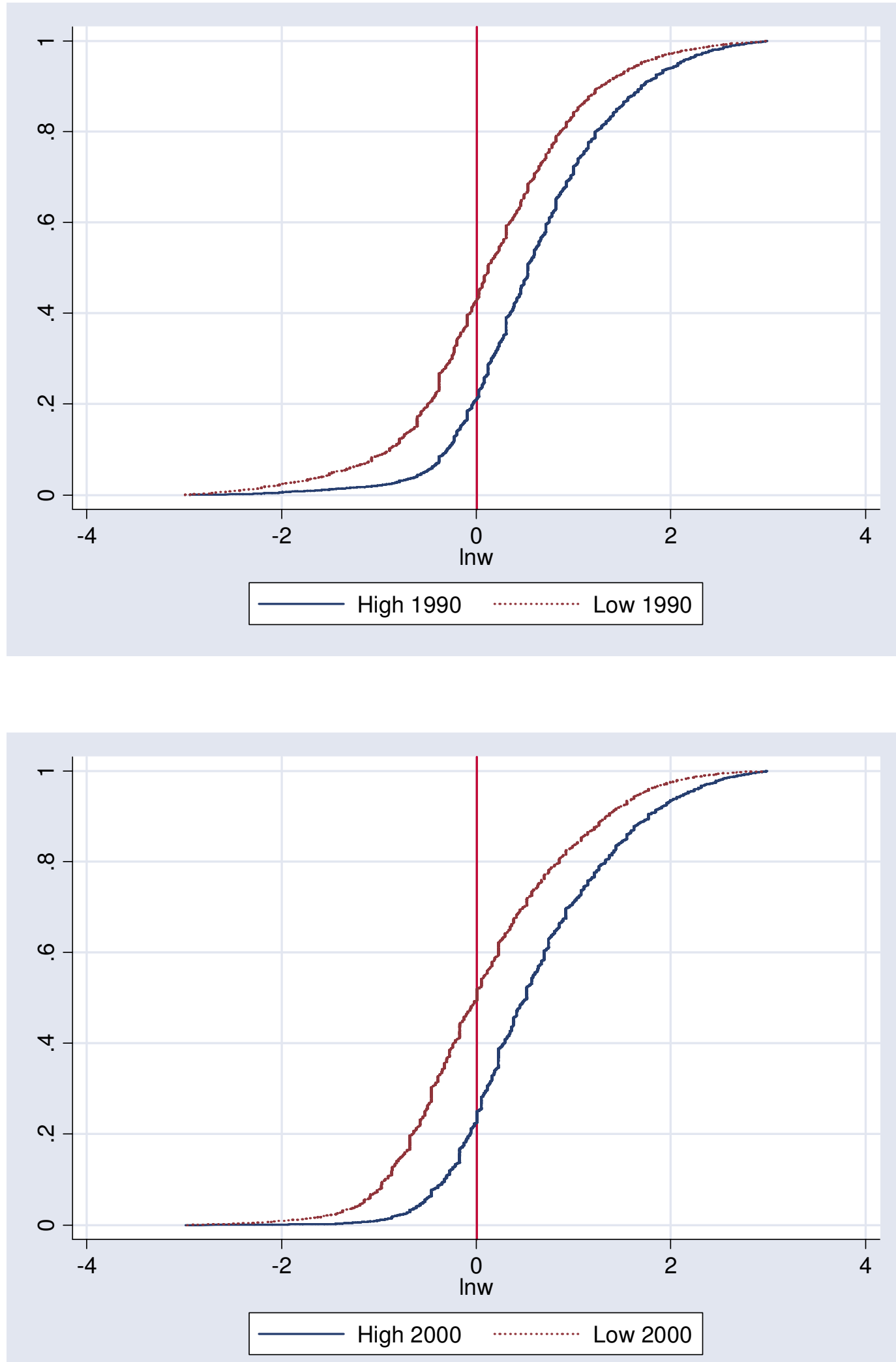
Figure 11:

Counterfactual Income Densities, High and Low-Exposure States, 1990 and 2000

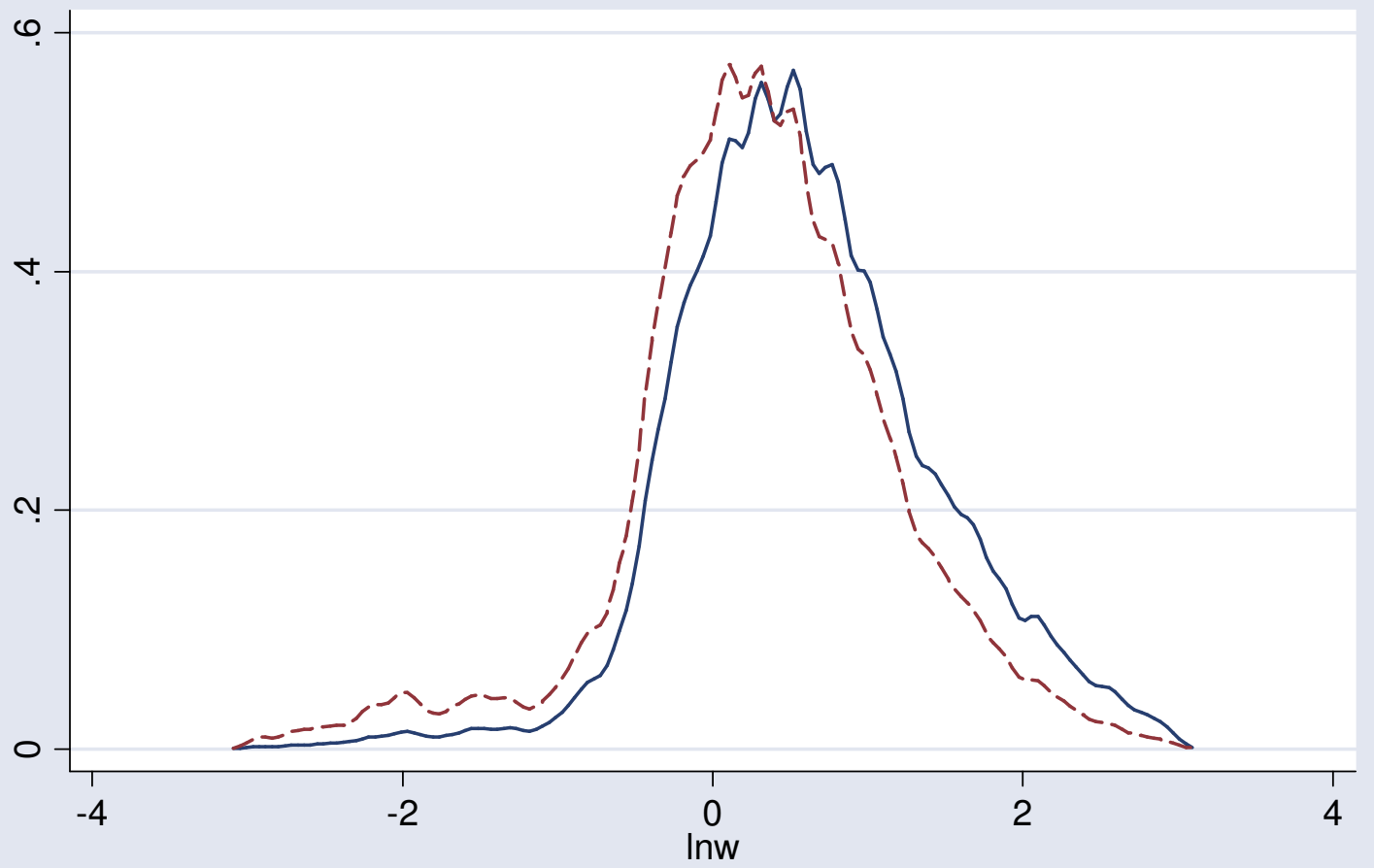

High 1990 ----- Low 1990

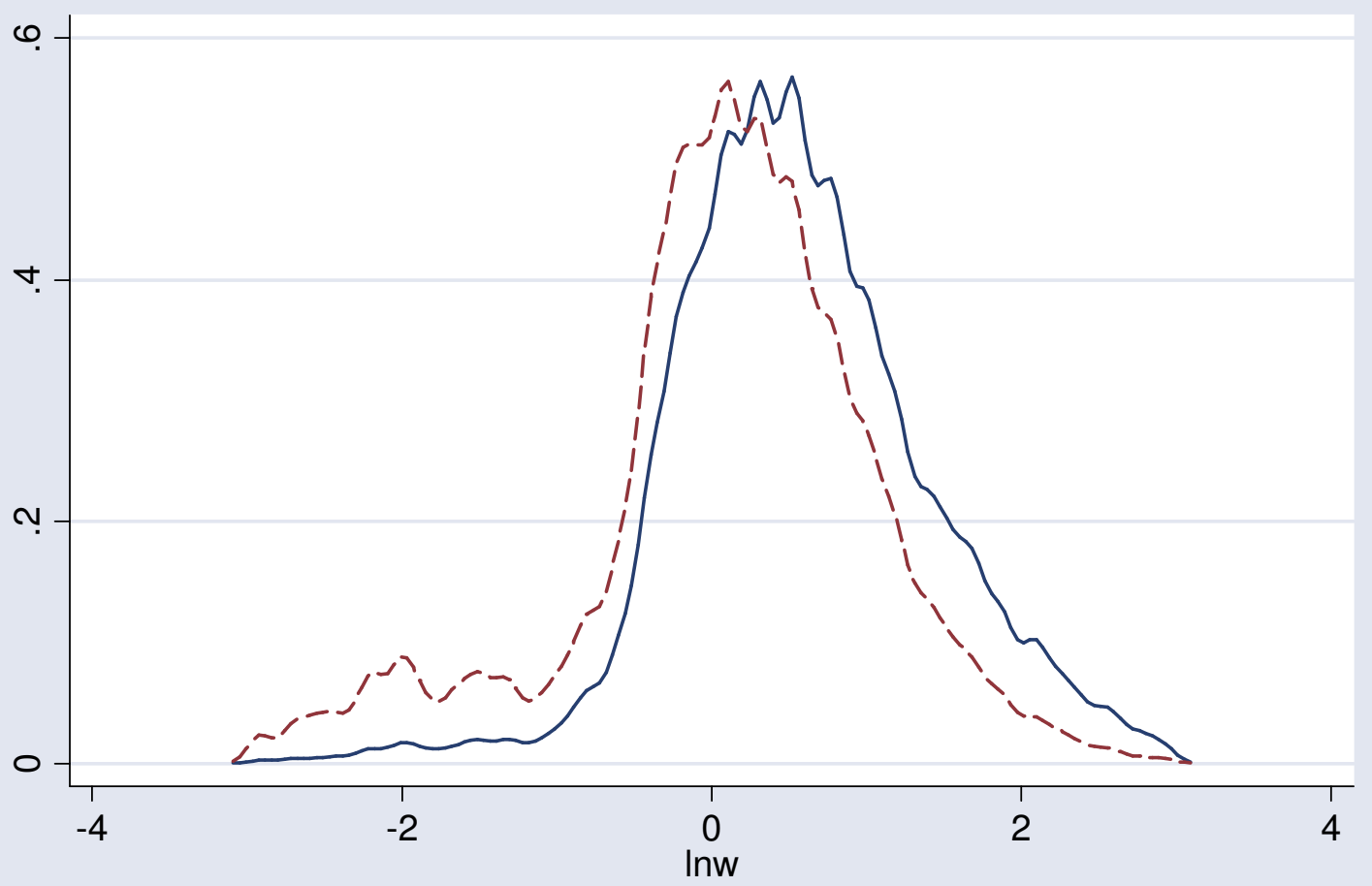

High 2000 - - - - Low 2000 
Figure 12: Counterfactual Cumulative Income Distributions, High and Low-Exposure States, 1990 and 2000
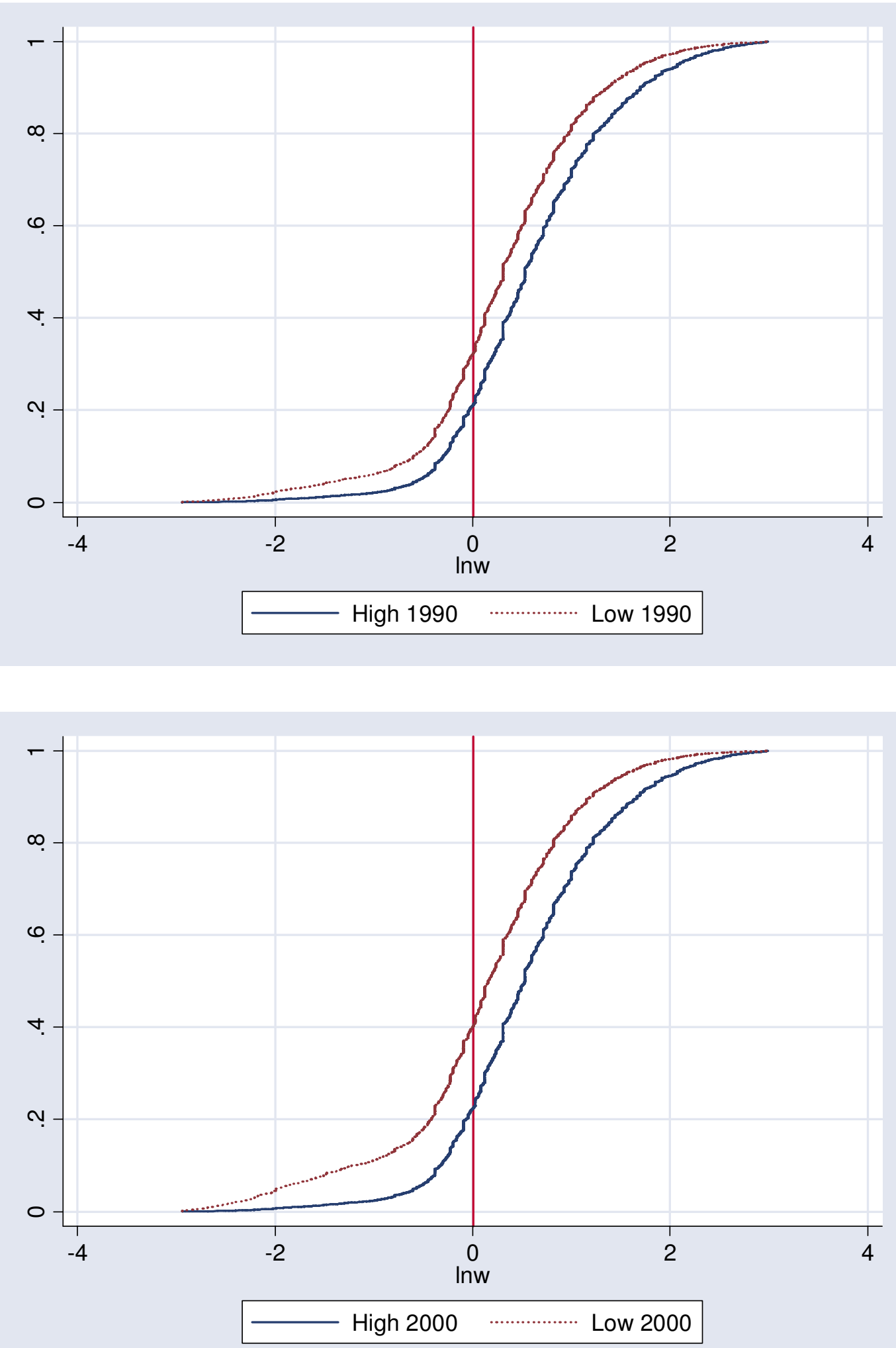
Figure 13: Estimated Change in Labor Income Densities, 1990 to 2000

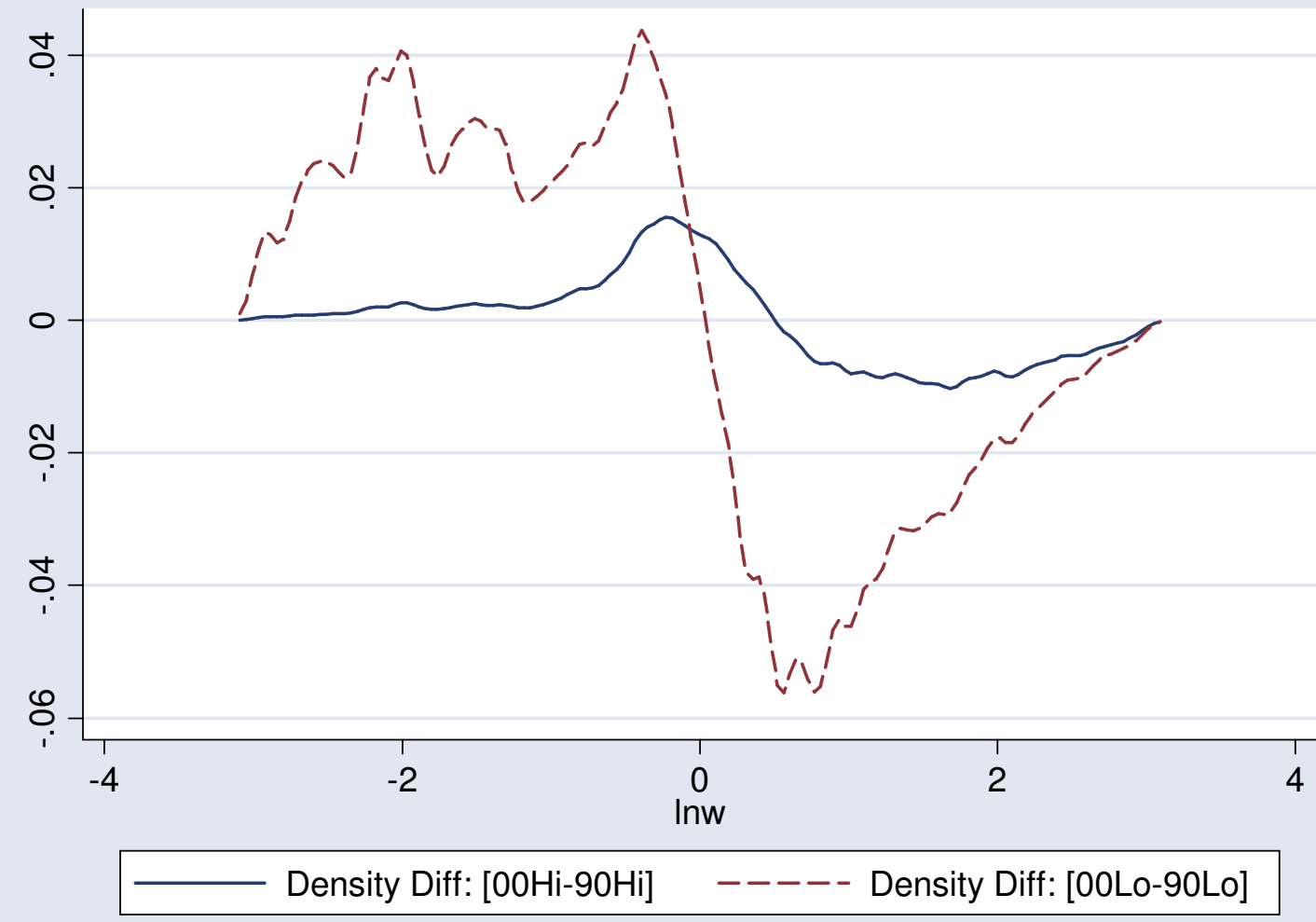

Figure 14: Double Difference in Labor Income Densities

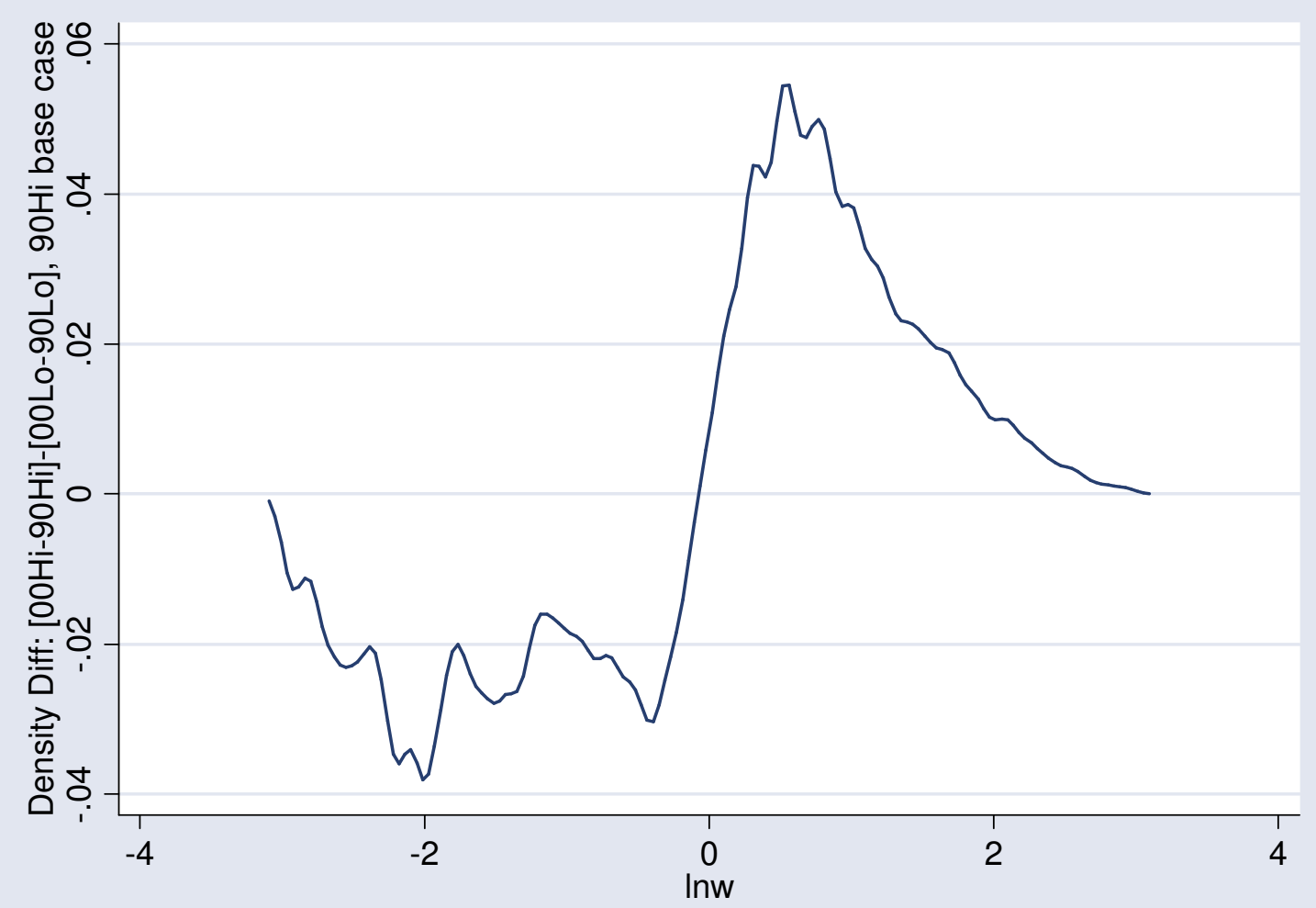


Figure 15: Double Difference in Labor Income Densities (Alternative Base Case)

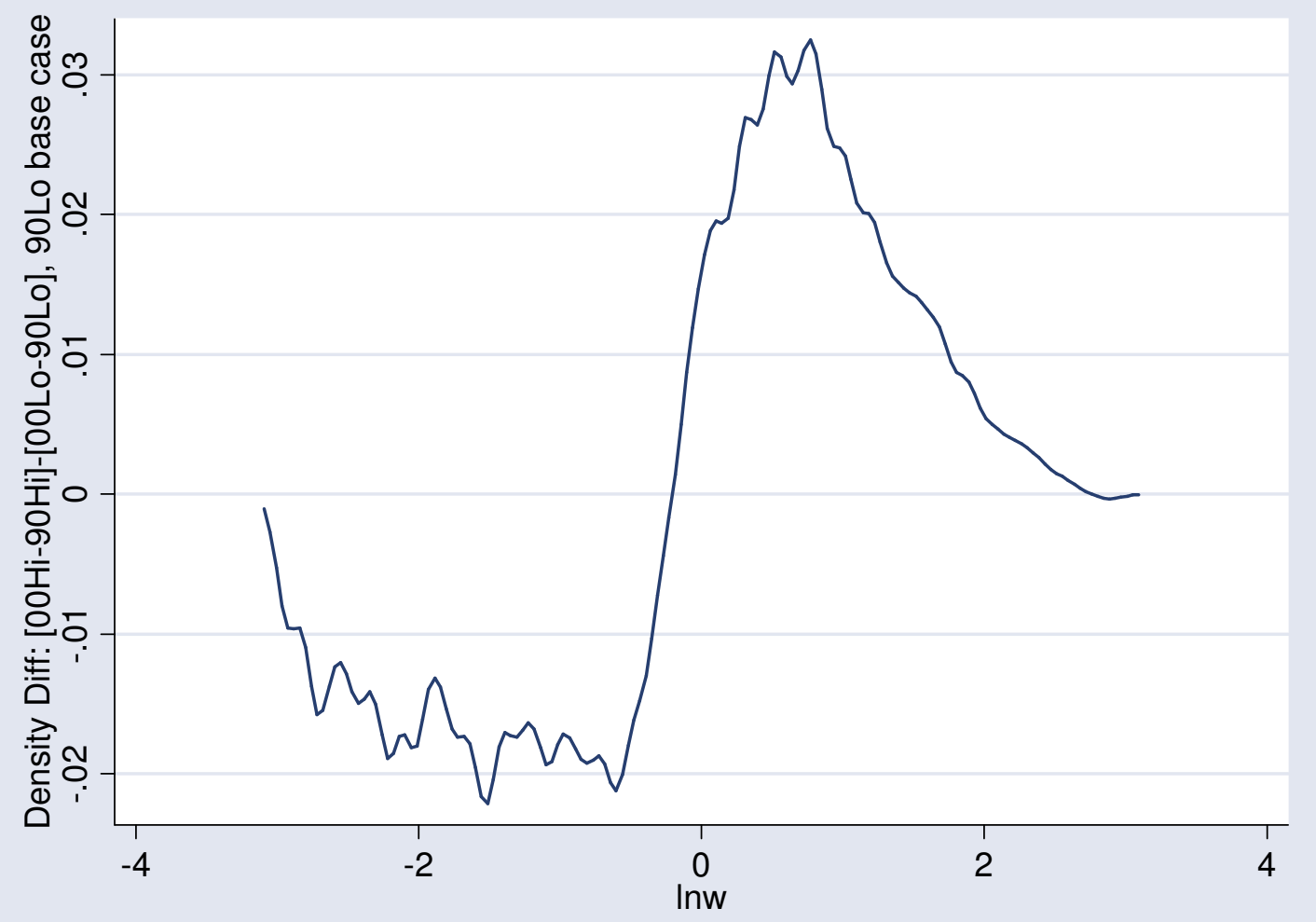

Figure 16: Double Difference in Total Labor Income Densities

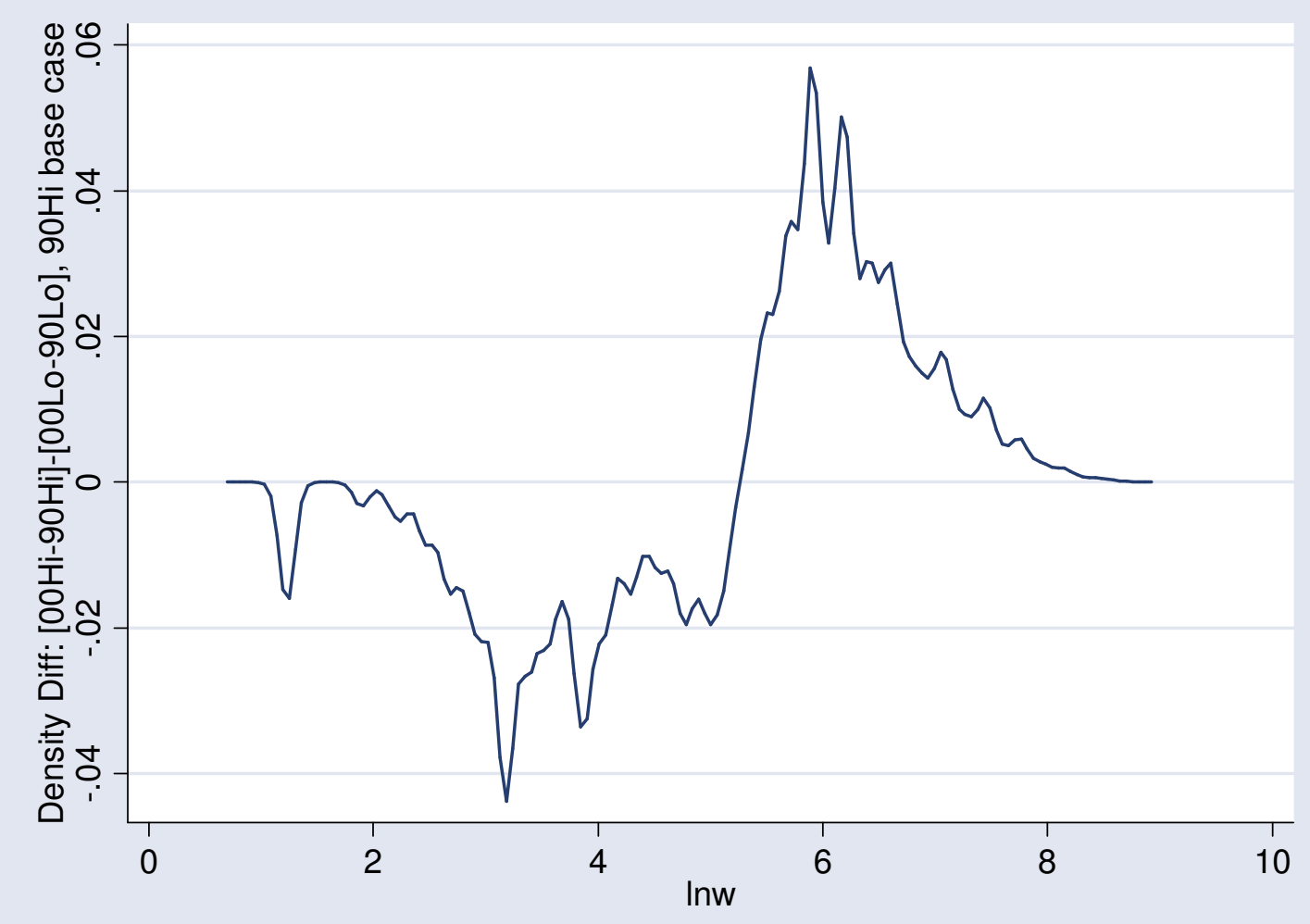


Figure 17: Estimated Change in Labor Income Densities, 1990 to 2000, with Observations Trimmed to Account for Selection into Work

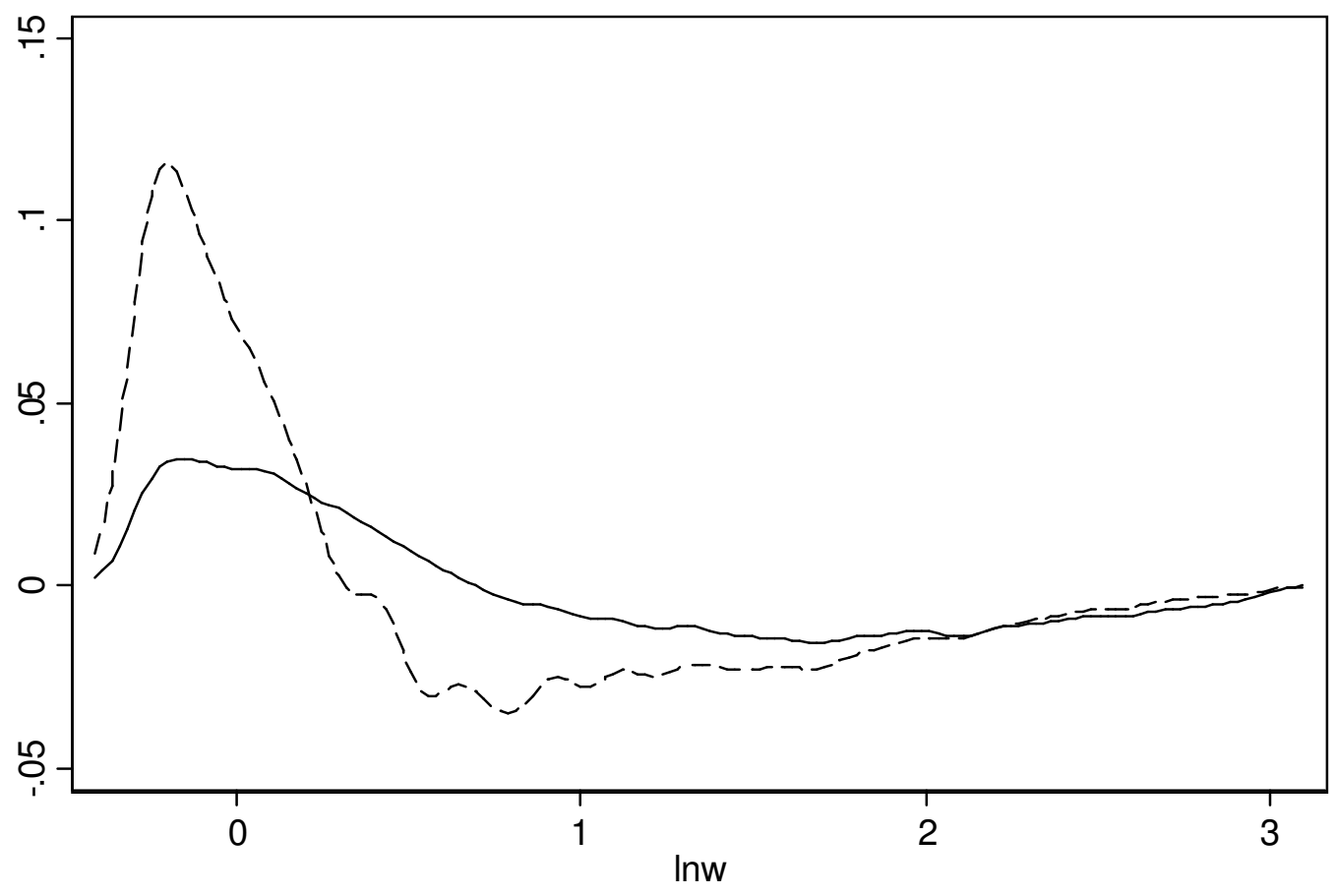

Density Diff: [00Hi-90Hi] - ---- Density Diff: [00Lo-90Lo]

Figure 18: Double Difference in Labor Income Densities, with Observations Trimmed to Account for Selection into Work

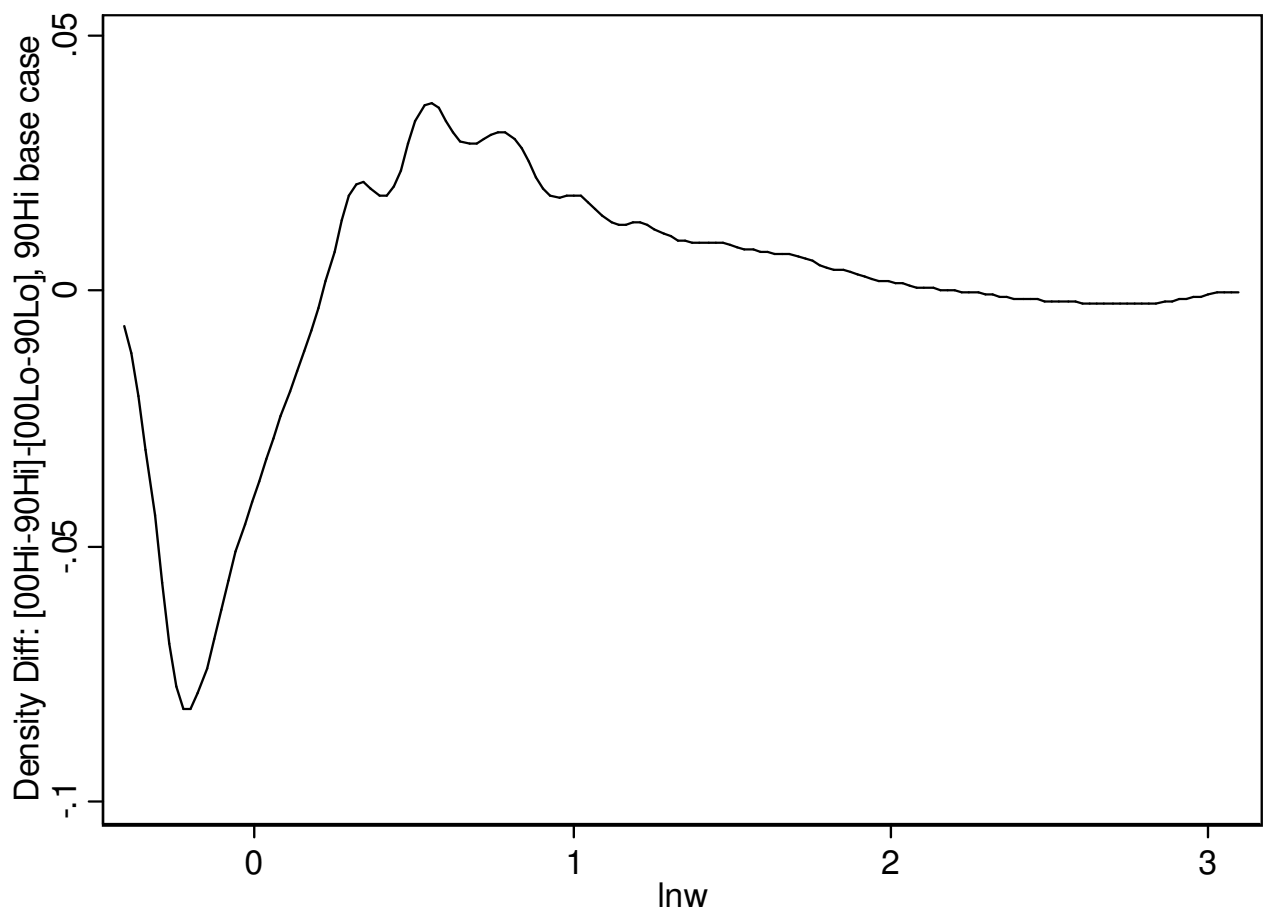

